\title{
Sexual Orientation and Neuroanatomy: An MRI Study of Gray Matter Differences in Homosexual, Bisexual, and Heterosexual Women and Men
}

Klimaj, V. ${ }^{1,2, *}$, Safron, A ${ }^{1,3,4}$, Sylva, D. ${ }^{5}$, Rosenthal, A.M. ${ }^{5}$, Li, M. ${ }^{6,7,8}$, Walter, M. ${ }^{6,7,8}$ Bailey, J.M. ${ }^{10}$

${ }^{1}$ Cognitive Science Program, Bloomington, IN, United States

${ }^{2}$ Department of Informatics, Indiana University, Bloomington, IN, U.S.

${ }^{3}$ Kinsey Institute, Indiana University, Bloomington, IN, United States

${ }^{4}$ Center for Psychedelic and Consciousness Research, Department of Psychiatry \& Behavioral Sciences, Johns

Hopkins University School of Medicine, Baltimore, MD

${ }^{5}$ Department of Psychiatry, Kaiser Permanente, US

${ }^{6}$ Clinical Affective Neuroimaging Laboratory, Leibniz Institute for Neurobiology, Magdeburg, Germany

${ }^{7}$ Otto-von-Guericke-University, Magdeburg, Germany

${ }^{8}$ Department of Psychiatry and Psychotherapy, University of Tuebingen, Tuebingen, Germany

${ }^{9}$ Department of Psychiatry and Psychotherapy, Jena University Hospital, Jena, Germany

${ }^{10}$ Department of Psychology, Northwestern University, Evanston, IL, United States

\begin{abstract}
In this study, we attempted to replicate past work focusing on differences in neuroanatomical structures between heterosexual and homosexual men and women. We also performed the first analyses of sexual orientation and neuroanatomy to include bisexual men and women. Sex differences in raw subcortical volumes were consistent with past work and a broader literature on sex differences, showing larger raw subcortical volumes in male groups than female groups. However, we did not confirm past findings showing larger raw volumes in heterosexual than in homosexual men in the left thalamus or right thalamus. Additionally, we did not confirm past findings showing thicker cortices in heterosexual men than in homosexual men in visual/occipital areas (right cuneus, right lingual gyrus, right pericalcarine cortex) or a frontal area (right pars triangularis). Exploratory whole-brain analyses revealed several areas of difference between women that may be of interest for future confirmatory research. Bisexual women had smaller volumes in a region of the olfactory tubercule than heterosexual women as well as a thicker right anterior insula region than homosexual women. Homosexual women had smaller volumes in regions of the inferior parietal lobule (IPL) than both heterosexual women and bisexual women. The functional relevance of these brain areas in terms of understanding female sexual orientation is unclear. However, based on these areas, future work may wish to consider the potential social, emotional, attentional, interoceptive, or general reward-related characteristics that may differentiate women with different attraction patterns. In contrast to previous work, no differences were found between groups of men (heterosexual, bisexual, or homosexual) in any of our analyses. Finally, in terms of whole-brain analyses of sex differences, heterosexual women had both thicker cortices and larger (relative to the whole brain) gray matter volume than heterosexual men in the superior frontal gyrus, in contrast to large-scale studies of sex difference. Although statistically significant at a stringent threshold (FWE-corrected), our whole-brain findings should be interpreted and generalized with caution. The heterogeneity of patterns across analyses of sexual orientation and brain structure (and even across studies of sex/gender and brain structure) suggests that findings may potentially depend upon particular sample characteristics, and potentially Type 1 error due to the testing of many different brain areas.
\end{abstract}




\section{Introduction}

The relationship between sexuality and brain structure can be approached from a wide variety of perspectives, including evolutionary, developmental, and experience-focused approaches. Some perspectives emphasize how sexual orientation may be influenced by genetic or prenatally-influenced aspects of biology and brain structure (Pillard \& Bailey, 1995, Bogaert $\&$ Skorska 2020). Other approaches emphasize how brain structure might change as a result of interactions with the environment (Lazar et al., 2005; Valk et al., 2017; Wenger et al., 2012). Determining the directions of influence between the brain and sexual attraction patterns would require large-scale developmental and longitudinal studies. However, understanding neuroanatomical differences between adults with different sexual orientations may be valuable for characterizing sources of group differences and informing further hypotheses across a wide variety of scientific perspectives.

\section{Gray matter differences between heterosexual and homosexual women and men}

We identified three studies that used MRI to study gray matter differences between heterosexual and homosexual men and women (Abé et al., 2014; Manzouri \& Savic, 2018; Ponseti et al., 2007). Overall, these studies were varied in their analytical approaches and findings, and so did not yield replicated patterns of differences between homosexual and heterosexual men, nor between homosexual and heterosexual women.

Two of these studies focused on structural differences between homosexual and heterosexual men (Abé et al., 2014; Manzouri \& Savic, 2018), both using data collected by Savic and colleagues. The first study by Abé and colleagues found that heterosexual men had thicker cortices than homosexual men in a number of regions, including visual/occipital areas (right cuneus, right lingual gyrus, right pericalcarine cortex), and a frontal area (right pars triangularis). Manzouri and Savic (2018) also found that heterosexual men had thicker cortices in the right cuneus than homosexual men. However, Manzouri and Savic also found differences in the opposite direction, with thicker cortices in homosexual men than in heterosexual men in areas including the left precuneus, the right rostral anterior cingulate, left superior parietal lobe, and the left inferior parietal lobe.

Both of these recent studies from Savic's research group also analyzed subcortical volume differences. Abé and colleagues found that homosexual men had smaller raw bilateral thalamic volumes than heterosexual men. Manzouri and Savic focused on proportional subcortical volumes (that is, subcortical volumes corrected for total brain volume). They found larger proportional volumes in (heterosexual and homosexual) women than in (heterosexual and homosexual) men in bilateral hippocampus and bilateral caudate, in contrast to a recent largescale studies of sex difference (Ritchie et al., 2018.). However, they found no differences in subcortical volumes based on sexual orientation - that is, no subcortical areas differed between heterosexual and homosexual men, or between heterosexual and homosexual women.

Finally, Ponseti and colleagues (2007) showed no differences between heterosexual and homosexual men in terms of gray matter structure. Instead, Ponseti and colleagues found structural differences between heterosexual and homosexual women. More specifically, Ponseti and colleagues found that homosexual women had lower gray matter concentration as compared to heterosexual women across several regions, including the perirhinal cortex, ventral premotor cortex, and cerebellar regions. These findings can not be directly compared to Manzouri and 
Savic (who did not measure gray matter concentration) or Abé and colleagues (who did not measure gray matter concentration, and also did not include homosexual women in their sample).

\section{Sex differences, sexual orientation, and brain structure}

It is difficult to determine the functional significance of existing findings distinguishing heterosexual and homosexual individuals based on gray matter structure, especially without replication. However, the hypothesis that neurohormonal factors contribute to sexual orientation suggests that research on sex differences in the brain might provide a source of context for the study of sexual orientation. Men, on average, tend to have larger brains and more gray matter volume throughout the brain (Ritchie et al., 2018.; Wierenga et al., 2020). Women, on the other hand, tend to have thicker cortices across the brain. Regional differences, however, are more inconsistent across studies and analytical approaches (Lotze et al., 2019; Ritchie et al., 2018.; Ruigrok et al., 2014).

In many ways, the study of sex differences has provided a basis for the study of sexual orientation, including with respect to brain structure. Indeed, many studies of sexual orientation suggest that non-heterosexual individuals show relatively sex-atypical characteristics in terms of behavior, personality, and even physical morphology (LeVay, 2010; Lippa, 2002, 2003; Rieger et al., 2008; Semenyna et al., 2018; Swaab, 2008; Xu et al., 2017). Others suggest "mosaic" patterns (or mixtures of sex-typical and sex-atypical features) among non-heterosexual individuals (Valentova et al., 2014). However, it is worth keeping in mind that assessing what constitutes "male typical" or "female typical" may not always be straightforward, including with regards to some aspects of brain structure. In addition, some distinguishing features of nonheterosexual groups may best be understood in the context of factors other than sex-typicality or atypicality. Additionally, due to the heterogeneity of findings described in the small existing literature on sexual orientation, it is difficult to make conclusions about sex atypicality of samesex attracted individuals in terms of gray matter structure without further research.

One important factor to consider in interpreting neuroanatomical studies of sex and sexual orientation is whether analyses of gray matter volume were controlled for participants' total brain volume. Analyses can be approached in two different ways. In looking for sex differences, we can identify which regions in men's brains larger or smaller than women's in terms of raw volume. Or, we can identify regions that are larger or smaller relative to the size of the brains that they are a part of. These are different approaches that both produce relevant results. Although men's brains are, on average, larger than women's brains, there are areas that tend to take up a larger relative portion of women's brains. Using raw versus brain-volumecorrected analytical approaches may therefore have different functional implications for sex differences and sexual orientation differences in terms of brain organization and potentially for behavior.

\section{Overview of the present study}

Overall, there is a small body of work on sexual orientation and gray matter structure (i.e. regional volume and thickness) yielding heterogeneous results that require replication. In this study, we aimed to replicate several sets of region-of-interest analyses focusing on subcortical volumes and cortical thickness in heterosexual and homosexual women and men (Abé et al., 2014; Manzouri \& Savic, 2018). Further, we performed novel analyses that included bisexual participants alongside heterosexual and homosexual groups. Here, we sought to identify novel structural across the whole brain between bisexual, heterosexual, and homosexual men and 
women. Finally, we included whole-brain tests of sex differences between heterosexual and homosexual women to facilitate comparisons between our sample and existing research focused on sex differences.

\section{Method}

The current study had two broad goals. The first was performing confirmatory analyses of two previous studies. From Abé and colleagues (2014), we attempted to replicate region-ofinterest (ROI) analyses of raw subcortical volume and regional cortical thickness that included heterosexual men, homosexual men, and heterosexual women. From Manzouri and Savic (2018) we attempted to replicate analyses of subcortical volume (corrected for intracranial volume) in heterosexual men, homosexual men, heterosexual women, and homosexual women. In performing these analyses, our replication attempts were not exact. That is, we used a different neuroimaging analysis toolbox (CAT12 for SPM, rather than FreeSurfer). One notable difference between these toolboxes is that subcortical volumes are calculated using different measures: CAT12 uses a measure of subcortical gray matter volume that uses voxel-by-voxel estimates, while FreeSurfer calculates the total volume of a subcortical segmentation (Gerrits et al., 2016). Robust differences may be expected to hold across such differences in analysis method between Fresurfer and CAT12; however, more subtle differences may not show up across analysis techniques (Gerrits et al., 2016).

The second aim of our study was performing exploratory analyses that included not only heterosexual and homosexual but also bisexual women and men. These analyses included exploratory ROI analyses in the same regions as in our replication attempts. We also performed exploratory analyses of gray matter volume and cortical thickness across the whole brain to look for within-sex orientation differences (i.e. comparing bisexual, heterosexual, and homosexual women to each other, and comparing bisexual, heterosexual, and homosexual men to each other). Both of these measures - gray matter volume and cortical thickness — are common neuroanatomical measures of cortical structure, with potentially different functional and developmental significance (Winkler et al., 2010). Finally, we included whole-brain analyses of sex differences between heterosexual men and women in order to compare our sample to largerscale studies of sex differences.

\section{Participants}

Participants were originally recruited for a study of brain activity and sexual orientation involving structural and functional MRI, genital arousal measurement, and subjective responses to erotic stimuli. Data from these other portions of the study have been published in several previous papers (Rosenthal et al., 2011; Safron et al., 2017, 2018, 2020).

In total, 155 participants were recruited ( 26 heterosexual women, 26 bisexual women, 24 homosexual women, 26 heterosexual men, 28 bisexual men, and 25 homosexual men) using online advertisements. More details on screening criteria can be found in Rosenthal et al. (2011) and Safron et al. (2017), along with information about participant sexual orientation, which was determined using both self-identity and a modified Kinsey scale. All methods were approved by the Institutional Review Board of Northwestern University and carried out in accordance with its guidelines, and participants provided informed consent for each part of the study. Distributions of demographic information (including Kinsey scores, ages, and race) can be viewed in Table 1. 


\section{Data acquisition and preprocessing Image acquisition and signal extraction}

A Siemens Trio 3T scanner with 12-channel RF head coil were used to collect T1weighted images $\left(1601-\mathrm{mm}\right.$ axial slices; $\mathrm{TR}=2.1 \mathrm{~ms}$; $\mathrm{TE}=4.38 \mathrm{~ms}$; flip angle $=15^{\circ}$; $\mathrm{FOV}=$ $220 \times 220 \mathrm{~mm} ; 256$ x 192 matrix). This was done after the collection of T2*-weighted gradientrecalled EPI images during a set of fMRI tasks involving picture and video viewing.

\section{MRI data preprocessing}

Preprocessing of MRI data was performed using CAT12 (http://dbm.neuro.unijena.de/cat12/) and SPM12 (Statistical Parametric Mapping, Welcome Trust Centre for Neuroimaging, http://www.fil.ion.ucl.ac.uk/spm), run on Matlab R2017b (Mathworks, Natick, MA, USA). Preprocessing steps were based on standard recommendations for CAT12 processing (Florian, Lüders, and Gaser, 2018) for voxel-based morphometry (for gray matter volume calculations) and surface-based morphometry (for cortical thickness calculations).

For gray matter volume calculations, standard protocols for voxel-based morphometry for CAT12 were followed. Before preprocessing, image registration was assessed and adjusted manually. The origin point was set to the anterior commissure for each subject, and images were reoriented to match the template image. Two subjects were excluded from further preprocessing due to insufficient head coverage in their scans. The remaining 153 participants' T1-weighted images were segmented into gray matter, white matter, and cerebrospinal fluid using SPM12 tissue probability maps and CAT12 default settings. To ensure the accuracy of segmentation, one slice was displayed and visually reviewed for each image, and sample homogeneity was checked using default CAT12 settings. Twelve subjects with the lowest correlations between volumes were checked for artifacts and image quality, including three participants whose correlations were below two standard deviations; no visible loss of quality was noted in any of these images. Images were smoothed using an $8 \times 8 \times 8$ full width at half maximum (FWHM) Gaussian kernel. Total intracranial volume (TIV), gray matter volume (GM), white matter volume (WM), and cerebrospinal fluid (CSF), were calculated for each subject.

For cortical thickness preprocessing, standard protocols for surface-based morphometry were followed (Florian, Lüders, and Gaser, 2018). The same images that had been registered and adjusted for VBM analyses were used, with the same exclusions. For cortical thickness calculations, image data was resampled and smoothed using a recommended $15 \mathrm{~mm}$ FWHM Gaussian kernel (Florian, Lüders, and Gaser, 2018).

\section{Background analyses: gross volumetric brain differences}

In order to provide information on gross brain volume differences between groups, several 2 x 3 (Sex * Orientation) between-group analyses of covariance (ANCOVAs) were used to assess the relationship between sex, sexual orientation, and global measures of brain volume. We used the following set of dependent variables: total intracranial volume (TIV), gray matter (GM), white matter (WM), cerebrospinal fluid (CSF), and white matter/gray matter ratio (WM/GM) (Table 3). Participant age was included as a covariate of no interest. Total intracranial volume was later used as a covariate in some of our analyses.

\section{ROI analyses: confirmatory and exploratory tests} Raw subcortical volumes (attempted replication of Abé and colleagues, 2014) 
We attempted to replicate findings from Abé and colleagues (2014) focused on the left and right putamen, hippocampus, amygdala, thalamus, and cerebellum. First, we performed exploratory one-way ANCOVAs that included heterosexual, homosexual, and bisexual men and women (six groups in total). Group differences were identified using Tukey's HSD tests. Age was included as a covariate of no interest. We followed this up with planned contrasts attempting to replicate the specific findings from Abé and colleagues (2014) which included only heterosexual women, heterosexual men, and homosexual men. Column 13 in Table 4 shows the differences that we were trying to replicate, reported by Abé and colleagues (2014). Most of these previous findings were sex differences (in a male $>$ female direction). However, we were particularly interested in the region that differentiated heterosexual and homosexual men. That is, we were attempting to confirm whether heterosexual men had larger raw left thalamus and right thalamus volumes than homosexual men.

\section{Subcortical volumes corrected for total intracranial volume (attempted replication} of Manzouri \& Savic, 2018)

We attempted to replicate findings from Manzouri and Savic (2018) focused on the left and right hippocampus and the left and right caudate. First, we performed exploratory one-way ANCOVAs that included heterosexual, homosexual, and bisexual men and women. Age and total intracranial volume were included as covariates of no interest. Group differences were identified using Tukey's HSD tests. We followed this up with planned contrasts attempting to replicate the findings from Manzouri and Savic (2018), which found sex differences in a female $>$ male direction (described in Table 5, column 13).

Cortical thickness regions (attempted replication of Abé and colleagues, 2014)

We attempted to replicate significant group differences in cortical thickness found by Abé and colleagues (2014) in a number of areas (left middle temporal, right pars triangularis, right lingual, right cuneus, right pericalracine). We also included tests of the other regions reported Abé and colleagues, in which differences between groups did not surive multiple comparisons (left superior temporal, right inferior temporal, right lateral orbitofrontal). In both their study and ours, these were defined using the Desikan-Killiany atlas. As with analyses of subcortical ROIs, first we performed exploratory one-way ANCOVAs on all of our groups (heterosexual men, heterosexual women, bisexual men, bisexual women, homosexual men, and homosexual women). Age, but not intracranial volume, was used as a covariate of no interest. Group differences were identified using Tukey's HSD tests. We followed these exploratory analyses with planned contrasts attempting to replicate the specific findings from Abé and colleagues (described in Table 6, column 13) in heterosexual men, homosexual men, and heterosexual women. We were most interested in the differences that had previously been found between heterosexual and homosexual men - that is, thicker cortices in heterosexual men than in homosexual men in right inferior temporal, right lateral orbitofrontal, right pars triangularis, right lingual, right cuneus, and right pericalcarine areas.

\section{Whole-brain analyses: exploratory analyses of sexual orientation and confirmatory analyses of sex differences}

In order to identify novel regional differences between men with different sexual orientations and women with different sexual orientations, we performed comparisons across the whole brain on two measures: gray matter volume and cortical thickness. For each of these measures, we compared male groups to each other (heterosexual vs. homosexual men, bisexual vs. heterosexual men, bisexual vs homosexual men) and female groups to each other 
(heterosexual vs. homosexual women, bisexual vs. heterosexual women, bisexual vs homosexual women). These contrasts were performed at with $\mathrm{p}<0.05$ Family-Wise Error (FWE) correction, which is considered relatively conservative (Friston et al., 1994), and with a voxel threshold of $\mathrm{k}$ $=2$.

Tests of regional gray matter volume were performed with both age and total intracranial volume as covariates, while tests of cortical thickness included only age as a covariate. This approach is based on previous recommendations to correct for brain volume and age in volumebased analyses, and age only in surface-based analyses (Barnes et al., 2010; Pintzka et al., 2015).

In addition to these whole-brain analyses of sexual orientation, we also performed wholebrain contrasts of heterosexual men and heterosexual women. Here, we aimed to see whether the sex differences (among heterosexuals) in our sample were consistent with previous large-scale studies of sex difference (Lotze et al., 2019; Ritchie et al., 2018.; Ruigrok et al., 2014a). In line with recent research, we corrected not only for age but also for total intracranial volume to search for areas of relatively greater volume in women as compared to men (Lotze et al., 2019).

\section{Results}

\section{Background data: gross volumetric brain differences}

There was a significant effect of sex on each of the volumetric measures (gray matter volume, white matter volume, cerebrospinal fluid, total intracranial volume, and ratio of white matter/gray matter), with men showing larger volumes than women (Table 3). There was also a significant effect of Sex * Orientation on white matter volume as well as ratios of white matter/gray matter volume. Post-hoc (Tukey's HSD) tests revealed several group differences. In terms of white matter, heterosexual men had larger volumes than all three groups of women (heterosexual women, bisexual women, and homosexual women). Bisexual men also had larger white matter volumes than all three groups of women (heterosexual, bisexual, and homosexual). Finally, homosexual men had larger white matter volumes than heterosexual women and bisexual women. In terms of ratios of white matter/gray matter volumes, bisexual men had more white matter relative to gray matter than both heterosexual and bisexual women. Heterosexual men also had a larger ratio of white matter to gray matter than both heterosexual and bisexual women. Finally, homosexual men had larger white matter to gray matter ratios than heterosexual women.

\section{ROI analyses: confirmatory and exploratory tests}

Raw subcortical volumes (attempted replication of Abé and colleagues, 2014)

One-way ANCOVAs were performed to test the effect of group on subcortical volumes (L/R putamen, L/R hippocampus, L/R amygdala, L/R thalamus, L/R cerebellum). Significant effects of group were found for all tests, and post-hoc (Tukey's HSD) tests revealed a number of differences, all in a male > female direction (Table 4). However, even though all of the differences were in a male $>$ female direction, the particular groups that differed from each other varied between tests. Follow-up planned contracts replicated a number of sex differences found by Abé and colleagues. However, none of the follow-up planned contrasts confirmed that heterosexual men have larger volumes than homosexual men in the left thalamus or right thalamus.

Subcortical volumes corrected for total intracranial volume (attempted replication of Manzouri \& Savic, 2018) 
We performed a series of one-way ANCOVAs to test the effect of group on subcortical volumes (L/R hippocampus and $\mathrm{L} / \mathrm{R}$ caudate) that had been corrected for total intracranial volume and age (Table 5). We found a significant effect of group on right caudate volume, with post hoc (Tukey's HSD) tests showing the bisexual women had larger volumes than heterosexual men. Follow-up planned contrasts replicated one finding from Manzouri and Savic: heterosexual women had larger right caudate volumes (relative to brain size) than both heterosexual and homosexual men.

Cortical thickness (attempted replication of Abé and colleagues, 2014)

We performed a series of one-way ANCOVAs to test for the effect of group on cortical thickness in a number of regions of interest - left middle temporal, left superior temporal, right inferior temporal, right lateral orbitofrontal, right pars triangularis, right lingual, right cuneus, and right pericalcarine areas. (Table 6). We found no effect of group on these volumes. Followup planned contrasts showed no differences replicating Abé and colleagues, who found that hetersosexual men had thicker cortices than homosexual men in all of the areas listed above except for the left middle and left superior temporal regions.

\section{Whole-brain analyses: exploratory analyses of sexual orientation and confirmatory analyses of sex differences}

Gray Matter Volume (corrected for total intracranial volume)

We found a number of areas that differed among women (Table 7). Heterosexual women had a larger right angular gyrus region than homosexual women, and bisexual women had a larger left supramarginal region than homosexual women. Additionally, heterosexual women had a larger right olfactory tubercule region than bisexual women. We also found one sex difference: heterosexual women had a larger left superior frontal gyrus region than heterosexual men. There were no whole-brain volume differences among male groups.

\section{Cortical Thickness}

We found that bisexual women had a thicker right anterior insular region than heterosexual women, and that heterosexual women had a thicker left superior frontal gyrus region than heterosexual men. There were no whole-brain cortical thickness differences among male groups.

\section{Appendix: Sex differences without correction for TIV and non-significant whole-brain maps}

Additional whole-brain analyses of sex differences in gray matter volume are included in the Appendix. Appendix Table 1 shows comparisons between heterosexual men and heterosexual women, without correction for total intracranial volume. These comparisons are significant at the relatively conservative threshold of $\mathrm{p}<.05$ FWE.

In addition to this table, we also include several uncorrected (at $p<.01$ ) maps depicting comparisons of gray matter volume between groups, generated using bsmpview (http://www.bobspunt.com/bspmview/). These include maps of comparisons between heterosexual men and women (Appendix Figure 1a, 1b), with and without correction for total intracranial volume. Additionally, we include maps of sexual orientation comparisons at $\mathrm{p}<.01$ (uncorrected) (Appendix Figure 2a, 2b, 3a, 3b). These maps are representations of general nonsignificant patterns in our groups and should not be interpreted as depicting significant findings. 


\section{Discussion}

We found expected sex differences in terms of larger raw subcortical volumes in men than in women. However, we did not replicate findings differentiating heterosexual and homosexual men in terms of either regional cortical thickness or subcortical volume (Abé et al., 2014; Manzouri \& Savic, 2018), which showed thicker cortices in a number of occipital areas in heterosexual men, as well as larger thalamic volumes in heterosexual men. In fact, we did not find any differences between men - either heterosexual, homosexual, or bisexual —in any of our confirmatory or exploratory analyses. However, our exploratory whole-brain analyses revealed several neuroanatomical differences between heterosexual, bisexual, and homosexual women. More specifically, bisexual women had thicker right anterior insular cortices than homosexual women, and smaller olfactory tubercule volumes than heterosexual women. Additionally, homosexual women had smaller inferior parietal regions than heterosexual and bisexual women.

\section{Attempted replications of regional cortical thickness and subcortical volume}

There may be a number of reasons for our unsuccessful attempts at replicating previous region-of-interest analyses in heterosexual and homosexual men. The most straightforward possibility is that a larger sample size would be required to replicate these differences. This is especially the case for our attempted ROI replication of Manzouri \& Savic, 2018. Although our sample was larger overall, Manzouri and Savic included more homosexual and heterosexual men and women in their study (see Table 2). However, there may be other explanations for our lack of replication. Firstly, a different image processing approach was used in our study. We used the CAT12 toolbox in SPM, whereas the studies we were attempting to replicate used FreeSurfer for their analyses. Although we might expect robust differences to be detected regardless of image processing approach, differences between imaging approaches could potentially lead to discrepant results (Grimm et al., 2015; Hutton et al., 2009; Righart et al., 2017). The dependence of particular findings on specific analysis pipelines is a more general issue in neuroimaging and science more generally (Botvinik-Nezer et al., 2019; Gorgolewski \& Poldrack, 2016), although it would be somewhat surprising if meaningfully robust effects depend on the particular software packages utilized. Yet, it may indeed be the case that a phenomenon is difficult to detect experimentally, while nonetheless having large impacts in ecological contexts, particularly when impacts are considered over extended periods of time.

An alternative (although not mutually exclusive) explanation for our non-replication may be that regional brain structure differences between sexual orientation groups could depend on demographic characteristics of the groups being analyzed. For example, it is possible that the same attraction pattern developed in two different cultures or cohorts may correspond to different characteristics in brain structure. Our subjects (recruited in the U.S.) and the subjects in the research we were trying to replicate (recruited in Sweden) could have differed in such ways. However, it is also possible that large-scale studies are needed to find more consistent regional differences between sexual orientation groups. A similar issue seems to be present in studies of sex differences and neuroanatomy, where larger-scale studies are beginning to show some consistent patterns of regional brain differences between men and women (Lotze et al., 2019; Ritchie et al., 2018.; Ruigrok et al., 2014), but with notable heterogeneity among findings.

Although our replication attempts focused on heterosexual men and women, we also included bisexual participants in our region of interest analyses to look for potential differences. We found one significant finding involving bisexual participants: bisexual women had larger 
(relative to the whole brain) right caudate volumes than heterosexual men. The implications of this difference are unclear. Speculatively, differences in caudate structure may reflect differences in reward related responding or sensitivity. Future work may wish to consider how different sensitivities to sexual reward throughout life may correspond to different likelihoods for developing monosexual versus bisexual arousal patterns.

Finally, it is important to note that we did not attempt replication of all of the analyses performed by either Manzouri and Savic (2018) or by Abé and colleagues (2014). We focused only on region-of-interest analyses in subcortical volume and cortical thickness. There were a number of other analyses performed in these studies (outlined in Table 2 in this paper), such as those focused on functional connectivity, that may be of interest for future replication attempts. Future work on sexual orientation and brain structure may also seek to confirm differences in midline structure thickness in homosexual men as compared to heterosexual men (Manzouri \& Savic, 2018), which included thicker cortices in homosexual men in the left precuneus and right rostral anterior cingulate along with the left superior and inferior parietal lobe. We did not perform specific analyses in these areas, which had been found on the whole brain level and so could not be defined with our atlas-based region-of-interest approach. However, it may also be worth noting that our exploratory whole-brain analyses of heterosexual and homosexual men did not show any of these differences reported by Manzouri and Savic.

\section{Exploratory whole brain analyses of gray matter volume and cortical thickness}

We found a number of group differences on the whole-brain level that may be of interest for future confirmatory research (Lorenz, 2020). One finding of particular interest was a thicker right anterior insular region in bisexual than in homosexual women. In a previous large-scale (n $=5,216$ ) study of sex differences, the right anterior insula was the only area in which men had thicker cortices than women (Ritchie et al., 2018), and so this may represent a relatively maletypical characteristic in bisexual women as compared to homosexual women. However, the functional significance of structural differences in the right anterior insula is unclear. The right anterior insula region has been associated with interoception, or sensing internal body states (Craig, 2009; Uddin et al., 2017). However, the potential neural connections between sexual orientation, sex/gender, and interoception would have to be explored in future work to provide clarity on what this difference might indicate.

Whole-brain analyses also found differences in inferior parietal areas between homosexual women as compared to bisexual and heterosexual women. Homosexual women had smaller volumes in the right inferior parietal lobule (and specifically the angular gyrus) as compared to heterosexual women, and smaller volumes in the left inferior parietal lobule (and specifically the supramarginal gyrus) as compared to bisexual women. The inferior parietal lobule is a hub structure in the brain, integrating multisensory information, and involved in selfperception/awareness, body schemas, attention, and social cogition (Berlucchi \& Aglioti, 1997; Igelström \& Graziano, 2017; Nobre, 2001; Saxe \& Wexler, 2005; Spence et al., 1997; Uddin et al., 2017). The functional significances of the orientation-related differences we found among women in the inferior parietal lobule are unclear. However, future investigations might consider how sexual orientation may co-develop with sense of self, the social self, aspects of attention, and other "higher-order" functions.

Surprisingly, there were no differences related to sexual orientation between male groups in our study, in either our whole-brain analyses or in the previously-described confirmatory ROI analyses. It is difficult to interpret this kind of null finding. Once again, it is possible that our 
sample was too small to detect differences between men. Speculatively, it is also possible that this pattern may be related to the tendency for men to exhibit greater variability in regional brain structure (Wierenga et al., 2020), which may make it more difficult to identify meaningful differences. Future research may wish to explore whether there may be greater variability in biological, behavioral, or social factors contributing to (or resulting from) particular sexual attraction patterns in men as compared to women.

In addition to looking for differences between sexual orientation groups, we also performed whole-brain analyses of heterosexual men and women to see if results would align with prior studies of sex differences. We found one region that differentiated heterosexual men and women in whole-brain analyses: heterosexual women had both proportionally larger gray matter volumes (relative to whole brain size) and thicker cortical tissue in their superior frontal gyrus than those found in heterosexual men. Although recent large-scale studies have identified some larger regional frontal volumes in women than in men (Lotze et al., 2019; Ruigrok et al., 2014b), those female-male differences were in the inferior frontal gyrus and middle frontal gyrus rather than the superior frontal gyrus. The superior frontal gyrus is broadly related to executive functions and premotor functions (Ball et al., 2011; Yuan \& Raz, 2014), involved in tasks such as planning actions. The significance of this neuroanatomical difference in our sample is unclear, especially in light of the fact that it has not been shown in larger studies of sex differences. It is also possible that this difference may reflect unique participant characteristics in our sample, who originally volunteered for an fMRI study on sexuality and sexual reward (Safron et al., 2017, 2018).

\section{Future directions}

Further research using larger samples may be needed to explore whether the brains of heterosexual, bisexual, and homosexual individuals show consistent regional differences across samples. In addition to including larger sample sizes, it may be important to consider how a variety of factors such as demographic characteristics, genetic predispositions, prenatal hormonal exposure, socialization, critical windows of sexual development, and individual experiences interact in the development of sexual preferences and the brain. Finally, fruitful insights about the development of orientation may arise by not only focusing on heterosexual and homosexual attraction patterns, but also considering bisexual and changing (i.e. fluid) attraction patterns (Diamond et al., 2017; Diamond, 2008). 


\section{AUTHOR CONTRIBUTIONS STATEMENT:}

A.S. was responsible for developing the analysis approach. D.S. and A.M.R. were responsible for data collection. V.K. and A.S. analyzed the data and wrote the manuscript. M.L. and M.W. provided neuroimaging analysis support. J.M.B. provided domain expertise and guidance through all stages of research and manuscript preparation. All authors have read and approved the final manuscript version.

COMPETING INTERESTS STATEMENT:

The authors of this manuscript have no conflicts of interest or competing interests relevant to this paper. 


\section{References}

Abé, C., Johansson, E., Allzén, E., \& Savic, I. (2014). Sexual orientation related differences in cortical thickness in male individuals. PloS One, 9(12), e114721. https://doi.org/10.1371/journal.pone.0114721

Ball, G., Stokes, P. R., Rhodes, R. A., Bose, S. K., Rezek, I., Wink, A.-M., Lord, L.-D., Mehta, M. A., Grasby, P. M., \& Turkheimer, F. E. (2011). Executive Functions and Prefrontal Cortex: A Matter of Persistence? Frontiers in Systems Neuroscience, 5. https://doi.org/10.3389/fnsys.2011.00003

Barnes, J., Ridgway, G. R., Bartlett, J., Henley, S. M. D., Lehmann, M., Hobbs, N., Clarkson, M. J., MacManus, D. G., Ourselin, S., \& Fox, N. C. (2010). Head size, age and gender adjustment in MRI studies: A necessary nuisance? NeuroImage, 53(4), 1244-1255. https://doi.org/10.1016/j.neuroimage.2010.06.025

Berlucchi, G., \& Aglioti, S. (1997). The body in the brain: Neural bases of corporeal awareness. Trends in Neurosciences, 20(12), 560-564. https://doi.org/10.1016/s0166-2236(97)01136-3

Botvinik-Nezer, R., Holzmeister, F., Camerer, C. F., Dreber, A., Huber, J., Johannesson, M., Kirchler, M., Iwanir, R., Mumford, J. A., Adcock, A., Avesani, P., Baczkowski, B., Bajracharya, A., Bakst, L., Ball, S., Barilari, M., Bault, N., Beaton, D., Beitner, J., ... Schonberg, T. (2019). Variability in the analysis of a single neuroimaging dataset by many teams [Preprint]. Neuroscience. https://doi.org/10.1101/843193

(Bud) Craig, A. D. (2009). How do you feel — now? The anterior insula and human awareness. Nature Reviews Neuroscience, 10(1), 59-70. https://doi.org/10.1038/nrn2555

Diamond, Lisa M., Dickenson, J. A., \& Blair, K. L. (2017). Stability of Sexual Attractions Across Different Timescales: The Roles of Bisexuality and Gender. Archives of Sexual Behavior, 46(1), 193-204. https://doi.org/10.1007/s10508-016-0860-X

Diamond, L.M. (2008). Sexual Fluidity: Understanding Women's Love and Desire. Harvard University Press.

Friston, K. J., Holmes, A. P., Worsley, K. J., Poline, J.-P., Frith, C. D., \& Frackowiak, R. S. J. (1994). Statistical parametric maps in functional imaging: A general linear approach. Human Brain Mapping, 2(4), 189-210. https://doi.org/10.1002/hbm.460020402

Gerrits, N. J. H. M., van Loenhoud, A. C., van den Berg, S. F., Berendse, H. W., Foncke, E. M. J., Klein, M., Stoffers, D., van der Werf, Y. D., \& van den Heuvel, O. A. (2016). Cortical Thickness, Surface Area and Subcortical Volume Differentially Contribute to Cognitive Heterogeneity in Parkinson's Disease. PLoS ONE, 11(2). https://doi.org/10.1371/journal.pone.0148852

Gorgolewski, K. J., \& Poldrack, R. A. (2016). A practical guide for improving transparency and reproducibility in neuroimaging research [Preprint]. Neuroscience. https://doi.org/10.1101/039354

Grimm, O., Pohlack, S., Cacciaglia, R., Winkelmann, T., Plichta, M. M., Demirakca, T., \& Flor, H. (2015). Amygdalar and hippocampal volume: A comparison between manual segmentation, Freesurfer and VBM. Journal of Neuroscience Methods, 253, 254-261. https://doi.org/10.1016/j.jneumeth.2015.05.024

Hutton, C., Draganski, B., Ashburner, J., \& Weiskopf, N. (2009). A comparison between voxel-based cortical thickness and voxel-based morphometry in normal aging. Neuroimage, 48(2-8), 371-380. https://doi.org/10.1016/j.neuroimage.2009.06.043

Igelström, K. M., \& Graziano, M. S. A. (2017). The inferior parietal lobule and temporoparietal junction: A network perspective. Neuropsychologia, 105, 70-83. https://doi.org/10.1016/j.neuropsychologia.2017.01.001

Lazar, S. W., Kerr, C. E., Wasserman, R. H., Gray, J. R., Greve, D. N., Treadway, M. T., McGarvey, M., Quinn, B. T., Dusek, J. A., Benson, H., Rauch, S. L., Moore, C. I., \& Fischl, B. (2005). Meditation experience is associated with increased cortical thickness. Neuroreport, 16(17), 1893-1897.

LeVay, S. (2010). Gay, Straight, and the Reason Why: The Science of Sexual Orientation. Oxford University Press.

Lippa, R. A. (2002). Gender-Related Traits of Heterosexual and Homosexual Men and Women. Archives of Sexual Behavior, 31(1), 83-98. https://doi.org/10.1023/A:1014035302843

Lippa, R. A. (2003). Are 2D:4D finger-length ratios related to sexual orientation? Yes for men, no for women. Journal of Personality and Social Psychology, 85(1), 179-188.

Lorenz, T. K. (2020). Reproducibility and Registration in Sexuality Research. Archives of Sexual Behavior, 49(2), 367-372. https://doi.org/10.1007/s10508-020-01650-w

Lotze, M., Domin, M., Gerlach, F. H., Gaser, C., Lueders, E., Schmidt, C. O., \& Neumann, N. (2019). Novel findings from 2,838 Adult Brains on Sex Differences in Gray Matter Brain Volume. Scientific Reports, 9(1), 1-7. https://doi.org/10.1038/s41598-018-38239-2

Manzouri, A., \& Savic, I. (2018a). Cerebral sex dimorphism and sexual orientation. Human Brain Mapping, 39(3), 1175-1186. https://doi.org/10.1002/hbm.23908 
Manzouri, A., \& Savic, I. (2018b). Cerebral sex dimorphism and sexual orientation. Human Brain Mapping, 39(3), 1175-1186. https://doi.org/10.1002/hbm.23908

Nobre, A. C. (2001). The attentive homunculus: Now you see it, now you don't. Neuroscience \& Biobehavioral Reviews, 25(6), 477-496. https://doi.org/10.1016/S0149-7634(01)00028-8

Pillard, R. C., \& Bailey, J. M. (1995). A biologic perspective on sexual orientation. The Psychiatric Clinics of North America, 18(1), 71-84.

Pintzka, C. W. S., Hansen, T. I., Evensmoen, H. R., \& Håberg, A. K. (2015). Marked effects of intracranial volume correction methods on sex differences in neuroanatomical structures: A HUNT MRI study. Frontiers in Neuroscience, 9. https://doi.org/10.3389/fnins.2015.00238

Ponseti, J., Siebner, H. R., Klöppel, S., Wolff, S., Granert, O., Jansen, O., Mehdorn, H. M., \& Bosinski, H. A. (2007). Homosexual women have less grey matter in perirhinal cortex than heterosexual women. PloS One, 2(1), e762. https://doi.org/10.1371/journal.pone.0000762

Rieger, G., Linsenmeier, J. A. W., Gygax, L., \& Bailey, J. M. (2008). Sexual orientation and childhood gender nonconformity: Evidence from home videos. Developmental Psychology, 44(1), 46-58. https://doi.org/10.1037/0012-1649.44.1.46

Righart, R., Schmidt, P., Dahnke, R., Biberacher, V., Beer, A., Buck, D., Hemmer, B., Kirschke, J. S., Zimmer, C., Gaser, C., \& Mühlau, M. (2017). Volume versus surface-based cortical thickness measurements: A comparative study with healthy controls and multiple sclerosis patients. PLOS ONE, 12(7), e0179590. https://doi.org/10.1371/journal.pone.0179590

Ritchie, S. J., Cox, S. R., Shen, X., Lombardo, M. V., Reus, L. M., Alloza, C., Harris, M. A., Alderson, H. L., Hunter, S., Neilson, E., Liewald, D. C. M., Auyeung, B., Whalley, H. C., Lawrie, S. M., Gale, C. R., Bastin, M. E., McIntosh, A. M., \& Deary, I. J. (n.d.). Sex Differences in the Adult Human Brain: Evidence from 5216 UK Biobank Participants. Cerebral Cortex. https://doi.org/10.1093/cercor/bhy109

Rosenthal, A. M., Sylva, D., Safron, A., \& Bailey, J. M. (2011). Sexual arousal patterns of bisexual men revisited. Biological Psychology, 88(1), 112-115. https://doi.org/10.1016/j.biopsycho.2011.06.015

Ruigrok, A. N. V., Salimi-Khorshidi, G., Lai, M.-C., Baron-Cohen, S., Lombardo, M. V., Tait, R. J., \& Suckling, J. (2014a). A meta-analysis of sex differences in human brain structure. Neuroscience and Biobehavioral Reviews, 39(100), 34-50. https://doi.org/10.1016/j.neubiorev.2013.12.004

Ruigrok, A. N. V., Salimi-Khorshidi, G., Lai, M.-C., Baron-Cohen, S., Lombardo, M. V., Tait, R. J., \& Suckling, J. (2014b). A meta-analysis of sex differences in human brain structure. Neuroscience and Biobehavioral Reviews, 39(100), 34-50. https://doi.org/10.1016/j.neubiorev.2013.12.004

Safron, A., Klimaj, V., Sylva, D., Rosenthal, A. M., Li, M., Walter, M., \& Bailey, J. M. (2018). Neural Correlates of Sexual Orientation in Heterosexual, Bisexual, and Homosexual Women. Scientific Reports, 8(1), 673. https://doi.org/10.1038/s41598-017-18372-0

Safron, A., Sylva, D., Klimaj, V., Rosenthal, A. M., \& Bailey, J. M. (2020). Neural Responses to Sexual Stimuli in Heterosexual and Homosexual Men and Women: Men's Responses Are More Specific. Archives of Sexual Behavior, 49(2), 433-445. https://doi.org/10.1007/s10508-019-01521-z

Safron, A., Sylva, D., Klimaj, V., Rosenthal, A. M., Li, M., Walter, M., \& Bailey, J. M. (2017). Neural Correlates of Sexual Orientation in Heterosexual, Bisexual, and Homosexual Men. Scientific Reports, 7. https://doi.org/10.1038/srep41314

Saxe, R., \& Wexler, A. (2005). Making sense of another mind: The role of the right temporo-parietal junction. Neuropsychologia, 43(10), 1391-1399. https://doi.org/10.1016/j.neuropsychologia.2005.02.013

Semenyna, S. W., Belu, C. F., Vasey, P. L., \& Honey, P. L. (2018). Not Straight and Not Straightforward: The Relationships Between Sexual Orientation, Sociosexuality, and Dark Triad Traits in Women. Evolutionary Psychological Science, 4(1), 24-37. https://doi.org/10.1007/s40806-017-0111-y

Spence, S. A., Brooks, D. J., Hirsch, S. R., Liddle, P. F., Meehan, J., \& Grasby, P. M. (1997). A PET study of voluntary movement in schizophrenic patients experiencing passivity phenomena (delusions of alien control). Brain: A Journal of Neurology, 120 ( Pt 11), 1997-2011. https://doi.org/10.1093/brain/120.11.1997

Swaab, D. F. (2008). Sexual orientation and its basis in brain structure and function. Proceedings of the National Academy of Sciences, 105(30), 10273-10274. https://doi.org/10.1073/pnas.0805542105

Uddin, L. Q., Nomi, J. S., Hebert-Seropian, B., Ghaziri, J., \& Boucher, O. (2017). Structure and function of the human insula. Journal of Clinical Neurophysiology: Official Publication of the American Electroencephalographic Society, 34(4), 300-306. https://doi.org/10.1097/WNP.0000000000000377 
Valentova, J. V., Kleisner, K., Havlíček, J., \& Neustupa, J. (2014). Shape differences between the faces of homosexual and heterosexual men. Archives of Sexual Behavior, 43(2), 353-361. https://doi.org/10.1007/s10508-013-0194-x

Valk, S. L., Bernhardt, B. C., Trautwein, F.-M., Böckler, A., Kanske, P., Guizard, N., Collins, D. L., \& Singer, T. (2017). Structural plasticity of the social brain: Differential change after socio-affective and cognitive mental training. Science Advances, 3(10), e1700489. https://doi.org/10.1126/sciadv.1700489

Wenger, E., Schaefer, S., Noack, H., Kühn, S., Mårtensson, J., Heinze, H.-J., Düzel, E., Bäckman, L., Lindenberger, U., \& Lövdén, M. (2012). Cortical thickness changes following spatial navigation training in adulthood and aging. NeuroImage, 59(4), 3389-3397. https://doi.org/10.1016/j.neuroimage.2011.11.015

Wierenga, L. M., Doucet, G., Dima, D., Agartz, I., Aghajani, M., Akudjedu, T., Albajes-Eizagirre, A., Alnaes, D., Alpert, K., Andreassen, O. A., Anticevic, A., Asherson, P., Banaschewski, T., Bargallo, N., Baumeister, S., Baur-Streubel, R., Bertolino, A., Bonvino, A., Boomsma, D., ... Tamnes, C. K. (2020). Greater male than female variability in regional brain structure across the lifespan [Preprint]. Neuroscience. https://doi.org/10.1101/2020.02.17.952010

Winkler, A. M., Kochunov, P., Blangero, J., Almasy, L., Zilles, K., Fox, P. T., Duggirala, R., \& Glahn, D. C. (2010). Cortical Thickness or Grey Matter Volume? The Importance of Selecting the Phenotype for Imaging Genetics Studies. NeuroImage, 53(3), 1135-1146. https://doi.org/10.1016/j.neuroimage.2009.12.028

Xu, Y., Norton, S., \& Rahman, Q. (2017). Sexual orientation and neurocognitive ability: A meta-analysis in men and women. Neuroscience and Biobehavioral Reviews, 83, 691-696. https://doi.org/10.1016/j.neubiorev.2017.06.014

Yuan, P., \& Raz, N. (2014). Prefrontal cortex and executive functions in healthy adults: A meta-analysis of structural neuroimaging studies. Neuroscience and Biobehavioral Reviews, 42, 180-192. https://doi.org/10.1016/j.neubiorev.2014.02.005 


\section{Figures and Tables}

Table 1. Participants Demographics: Age, Race, and Kinsey Score

\begin{tabular}{|c|c|c|c|c|c|c|}
\hline & \multicolumn{3}{|l|}{ Men } & \multicolumn{3}{|l|}{ Women } \\
\hline & $\begin{array}{l}\text { Heterosexual } \\
\mathbf{N}=\mathbf{2 6}\end{array}$ & $\begin{array}{l}\text { Bisexual } \\
\mathbf{N}=\mathbf{2 8}\end{array}$ & $\begin{array}{l}\text { Homosexual } \\
\mathbf{N}=\mathbf{2 5}\end{array}$ & $\begin{array}{l}\text { Heterosexual } \\
\mathbf{N}=\mathbf{2 6}\end{array}$ & $\begin{array}{l}\text { Bisexual } \\
\mathbf{N}=\mathbf{2 6}\end{array}$ & $\begin{array}{l}\text { Homosexual } \\
\mathbf{N}=\mathbf{2 4}\end{array}$ \\
\hline Age & $\begin{array}{l}32.3 \\
\mathrm{SD}=6.75 \\
\text { range }=25-48\end{array}$ & $\begin{array}{l}37.5 \\
\mathrm{SD}=8.32 \\
\text { range }=26-50\end{array}$ & $\begin{array}{l}33.1 \\
\mathrm{SD}=6.5 \\
\text { range }=26-50\end{array}$ & $\begin{array}{l}29.6 \\
\mathrm{SD}=5.99 \\
\text { range }=25-46\end{array}$ & $\begin{array}{l}30.3 \\
\mathrm{SD}=6.41 \\
\text { range }=21-48\end{array}$ & $\begin{array}{l}29.0 \\
\mathrm{SD}=3.12 \\
\text { range }=25-38\end{array}$ \\
\hline $\begin{array}{l}\text { Race } \\
\text { (\% White / \% Other } \\
\text { Self-Identified Race) }\end{array}$ & $62 \% / 38 \%$ & $54 \% / 46 \%$ & $71 \% / 29 \%$ & $60 \% / 40 \%$ & $73 \% / 27 \%$ & $79 \% / 31 \%$ \\
\hline Kinsey Score & $\begin{array}{l}0.4 \\
\mathrm{SD}=0.46 \\
\text { range }=0-1.5\end{array}$ & $\begin{array}{l}3.2 \\
\mathrm{SD}=0.85 \\
\text { range }=2-4.5\end{array}$ & $\begin{array}{l}5.7 \\
S D=0.46 \\
\text { range }=5-6\end{array}$ & $\begin{array}{l}0.8 \\
\mathrm{SD}=0.6 \\
\text { range }=0-2\end{array}$ & $\begin{array}{l}2.63 \\
\mathrm{SD}=0.7 \\
\text { range }=2-4.5\end{array}$ & $\begin{array}{l}5.2 \\
S D=0.68 \\
\text { range }=4-6\end{array}$ \\
\hline
\end{tabular}

$\mathrm{SD}=$ standard deviation. Race/ethnicity was self-identified by participants as either White, Black, Latino/a, Asian, or self-described/other. A more detailed description of these demographics within each sex and orientation group can be found in Safron et al. $(2017,2018)$. 
Table 2. Comparing analysis approaches in studies of neuroanatomy and sexual orientation

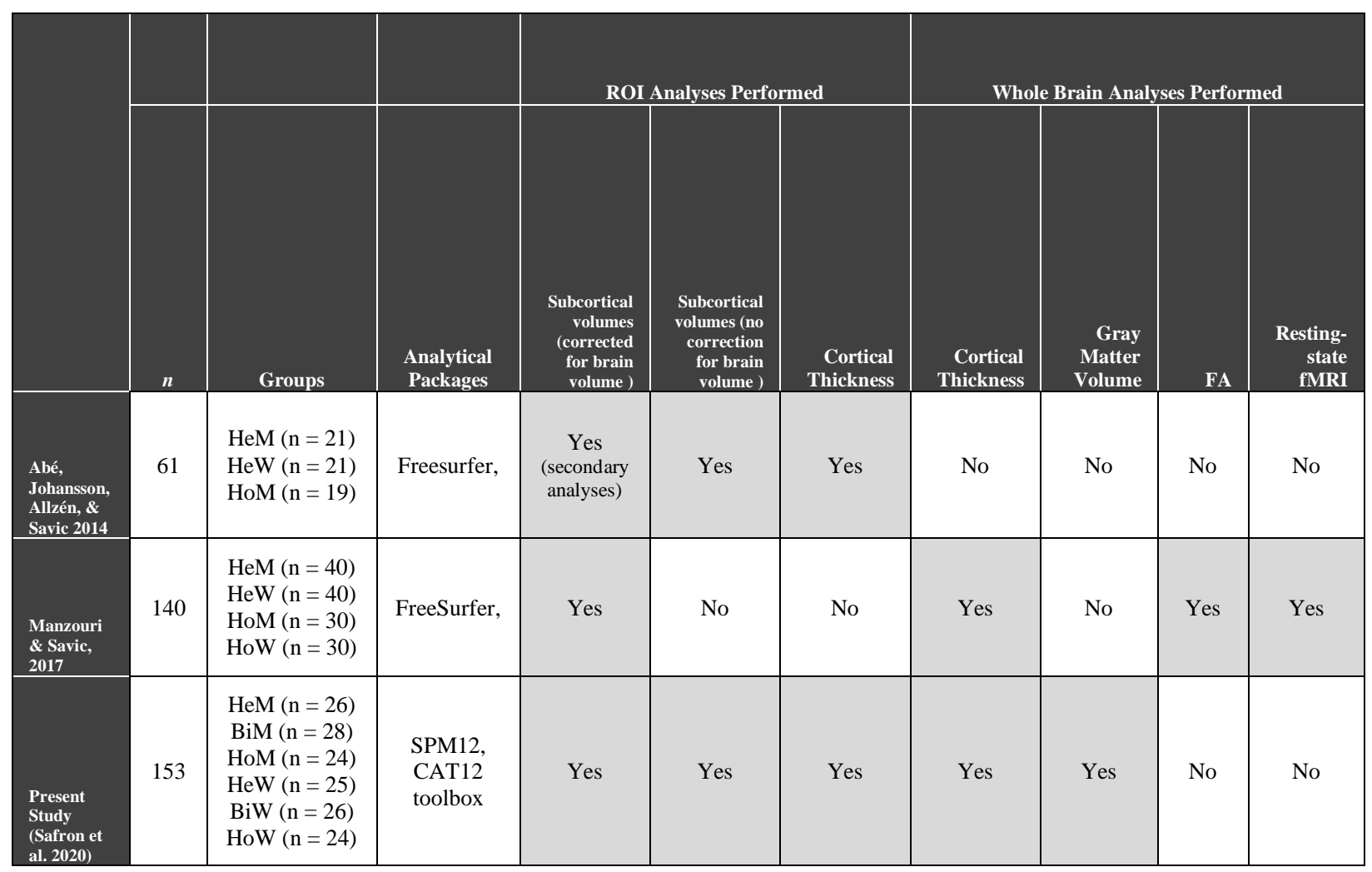

This table provides an overview of the participant sample and analyses approaches included in both of the studies that we attempted to partially replicate, as well as in the research discussed in this paper. $\mathrm{HeM}=$ heterosexual men, $\mathrm{HeW}=$ heterosexual women, $\mathrm{HoM}=$ homosexual men, $\mathrm{HoW}=$ homosexual women, $\mathrm{BiM}=$ bisexual men, $\mathrm{BiW}=$ bisexual women. $\mathrm{FA}=$ fractional anisotropy. TIV $=$ total intracranial volume, a measure that is closely related to brain volume. 
Table 3: Gross Measures of Brain Anatomy: Volumetric Means and Differences

\begin{tabular}{|c|c|c|c|c|c|c|c|c|c|c|}
\hline & $\begin{array}{l}\mathrm{HeM} \\
\mathrm{N}=\mathbf{2 6}\end{array}$ & $\begin{array}{l}\mathrm{BiM} \\
\mathrm{N}=\mathbf{2 8}\end{array}$ & $\begin{array}{l}\text { HoM } \\
\mathrm{N}=\mathbf{2 4}\end{array}$ & $\begin{array}{l}\text { HeW } \\
N=25\end{array}$ & $\begin{array}{l}\mathrm{BiW} \\
\mathrm{N}=\mathbf{2 6}\end{array}$ & $\begin{array}{l}\text { HoW } \\
\mathrm{N}=\mathbf{2 4}\end{array}$ & $\begin{array}{l}\text { Sex: } \\
\text { F(df) } \\
\text { p-value }\end{array}$ & $\begin{array}{l}\text { Orient: } \\
\text { F(df) } \\
\text { p-value }\end{array}$ & $\begin{array}{l}\text { Sex * } \\
\text { Orient: } \\
\text { F(df) } \\
\text { p-value }\end{array}$ & Direction of Difference \\
\hline $\begin{array}{l}\text { Total } \\
\text { intra- } \\
\text { cranial } \\
\text { volume } \\
\text { (TIV) } \\
\end{array}$ & $\begin{array}{l}1595.81 \\
\pm \\
23.56\end{array}$ & $\begin{array}{l}1579.26 \\
\pm \\
24.20\end{array}$ & $\begin{array}{l}1549.02 \\
\pm \\
24.57\end{array}$ & $\begin{array}{l}1395.94 \\
\pm \\
24.32\end{array}$ & $\begin{array}{l}1381.05 \\
\pm \\
23.72\end{array}$ & $\begin{array}{l}1415.66 \\
\pm \\
24.98\end{array}$ & $\begin{array}{l}72.94 \\
(1,146) \\
<.001\end{array}$ & $\begin{array}{l}0.253 \\
(2,146) \\
0.777\end{array}$ & $\begin{array}{l}1.23 \\
(2,146) \\
0.300\end{array}$ & $\begin{array}{l}\text { Sex: } \\
\text { Male > Female }\end{array}$ \\
\hline $\begin{array}{l}\text { Gray } \\
\text { matter } \\
(\text { GM) }\end{array}$ & $\begin{array}{l}722.55 \\
\pm \\
10.42\end{array}$ & $\begin{array}{l}709.23 \\
\pm \\
10.70\end{array}$ & $\begin{array}{l}709.41 \\
\pm \\
10.86\end{array}$ & $\begin{array}{l}661.42 \\
\pm \\
10.75\end{array}$ & $\begin{array}{l}649.63 \\
\pm \\
10.49\end{array}$ & $\begin{array}{l}642.58 \\
\pm \\
11.04\end{array}$ & $\begin{array}{l}46.48 \\
(1,146) \\
<.001\end{array}$ & $\begin{array}{l}1.25 \\
(2,146) \\
0.289\end{array}$ & $\begin{array}{l}0.064 \\
(2,146) \\
0.936\end{array}$ & $\begin{array}{l}\text { Sex: } \\
\text { Male > Female }\end{array}$ \\
\hline $\begin{array}{l}\text { White } \\
\text { matter } \\
\text { (WM) }\end{array}$ & $\begin{array}{l}552.33 \\
\pm \\
9.44\end{array}$ & $\begin{array}{l}544.41 \\
\pm \\
9.73\end{array}$ & $\begin{array}{l}523.20 \\
\pm \\
9.85\end{array}$ & $\begin{array}{l}469.71 \\
\pm \\
9.99\end{array}$ & $\begin{array}{l}470.61 \\
\pm \\
9.51\end{array}$ & $\begin{array}{l}487.25 \\
\pm \\
10.01\end{array}$ & $\begin{array}{l}58.38 \\
(1,145) \\
<.001\end{array}$ & $\begin{array}{l}0.18(2,145) \\
0.836\end{array}$ & $\begin{array}{l}3.24 \\
(2,145) \\
0.042\end{array}$ & $\begin{array}{l}\text { Sex: } \\
\text { Male > Female } \\
\text { Sex*Orient: } \\
\mathrm{HeM}>\mathrm{HeW}, \mathrm{BiW}, \& \mathrm{HoW} \\
\mathrm{BiM}>\mathrm{HeW}, \mathrm{BiW}, \& \mathrm{HoW} \\
\mathrm{HoM}>\mathrm{HeW} \& \mathrm{BiW}\end{array}$ \\
\hline $\begin{array}{l}\text { Cerebro- } \\
\text { spinal } \\
\text { fluid }\end{array}$ & $\begin{array}{l}320.88 \\
\pm \\
9.02\end{array}$ & $\begin{array}{l}324.06 \\
\pm \\
9.27\end{array}$ & $\begin{array}{l}316.12 \\
\pm \\
9.41\end{array}$ & $\begin{array}{l}271.09 \\
\pm \\
9.31\end{array}$ & $\begin{array}{l}261.33 \\
\pm \\
9.09\end{array}$ & $\begin{array}{l}286.70 \\
\pm \\
9.57\end{array}$ & $\begin{array}{l}35.46 \\
(1,146) \\
<.001\end{array}$ & $\begin{array}{l}0.45 \\
(2,146) \\
0.640\end{array}$ & $\begin{array}{l}1.67 \\
-(2,146) \\
0.193\end{array}$ & Sex: Male > Female \\
\hline $\begin{array}{l}\text { White } \\
\text { matter/ } \\
\text { Gray } \\
\text { mater } \\
\text { ratio } \\
\text { (WM/GM) }\end{array}$ & $\begin{array}{l}.765 \pm \\
.009\end{array}$ & $\begin{array}{l}.770 \pm \\
.010\end{array}$ & $\begin{array}{l}.739 \pm \\
.010\end{array}$ & $\begin{array}{l}.702 \pm \\
.010\end{array}$ & $\begin{array}{l}0.724 \pm \\
.009\end{array}$ & $\begin{array}{l}.757 \pm \\
.010\end{array}$ & $\begin{array}{l}13.68 \\
(1,146) \\
<.001\end{array}$ & $\begin{array}{l}1.44 \\
(2,146) \\
0.241\end{array}$ & $\begin{array}{l}10.03 \\
(2,146) \\
<.001\end{array}$ & $\begin{array}{l}\text { Sex: Male > Female } \\
\text { Sex*Orient: } \\
\mathrm{BiM}>\mathrm{HeW} \& \mathrm{BiW} \\
\mathrm{HeM}>\mathrm{HeW} \& \mathrm{BiW} \\
\mathrm{HoW}>\mathrm{HeW}\end{array}$ \\
\hline
\end{tabular}

Table 3 provides general volumetric information describing our groups. $\mathrm{HeM}=$ heterosexual men, $\mathrm{BiM}=$ bisexual men, $\mathrm{HoM}=$ homosexual men, $\mathrm{HeW}=$ heterosexual women, $\mathrm{BiW}=$ bisexual women, $\mathrm{HoW}=$ homosexual women. Mean volume (in $\mathrm{cm}^{3}$ ) and standard error are included for each group, corrected for participant age. The main effects and interaction of $2 \times 3$ ANCOVA are shown (with Sex, Orientation, and Sex*Orientation), with participant age included as a covariate of no interest. All volumetric measures, as well as the ratio of white matter to gray matter, was higher in males than in females. There were no within-sex differences based on orientation (that is, no groups of men differed from each other, and no groups of women differed from each other). Perhaps notably, bisexual men had the largest WM/GM ratios, although these did not differ significantly from heterosexual or homosexual men. 
Table 4. Differences in Raw Subcortical Volumes; Attempted Replication of Abé, Johansson, Allzén, \& Savic 2014

\begin{tabular}{|c|c|c|c|c|c|c|c|c|c|c|c|c|}
\hline & $\begin{array}{l}\mathrm{HeM} \\
N=26\end{array}$ & $\begin{array}{l}\text { HeW } \\
N=24\end{array}$ & $\begin{array}{l}B i M \\
N=28\end{array}$ & $\begin{array}{l}B i W \\
N=26\end{array}$ & $\begin{array}{l}\text { HoM } \\
N=24\end{array}$ & $\begin{array}{l}\text { HoW } \\
N=24\end{array}$ & $F(d f)$ & $p$-value & $\eta p^{2}$ & $\begin{array}{l}\text { Differences } \\
\text { in present sample } \\
\text { (Exploratory ANCOVAs) } \\
\text { Tests include: HeW, HeM, BiW, } \\
\text { BiM, HeM, HoM }\end{array}$ & $\begin{array}{l}\text { Follow-up planned } \\
\text { contrasts: attempted } \\
\text { replication of Abé, } \\
\text { Johansson, Allzén, \& } \\
\text { Savic } 2014 \\
\text { Tests include: HeW, HeM, } \\
\text { HoM }\end{array}$ & $\begin{array}{l}\begin{array}{l}\text { Findings present in Abé, } \\
\text { Johansson, Allzén, \& } \\
\text { Savic } 2014 \\
\text { Tests include: HeW HeM, } \\
\text { HoM) }\end{array}\end{array}$ \\
\hline \multicolumn{13}{|c|}{ Structural volume } \\
\hline L putamen & $\begin{array}{l}4.57 \pm \\
.08\end{array}$ & $\begin{array}{l}4.09 \pm \\
.08\end{array}$ & $\begin{array}{l}4.45 \pm \\
.08\end{array}$ & $\begin{array}{l}4.07 \pm \\
.08\end{array}$ & $\begin{array}{l}4.42 \\
\pm .09\end{array}$ & $\begin{array}{l}4.06 \pm \\
.09\end{array}$ & $6.933(6,146)$ & $<.0001$ & 0.19 & $\begin{array}{l}\mathrm{HeM} \& \mathrm{BiM}>\text { all female groups; } \\
\mathrm{HoM}>\mathrm{BiW}\end{array}$ & $\begin{array}{l}\text { HeM }>\text { HeW } \\
\text { HoM }>\mathrm{HeW} \\
(\mathrm{t}=4.108, \mathrm{p}<.001 ; \\
\mathrm{t}=2.7402, \mathrm{p}=.007)\end{array}$ & $\begin{array}{l}\mathrm{HeM}>\mathrm{HeW}^{*} \\
\mathrm{HoM}>\mathrm{HeW}^{*}\end{array}$ \\
\hline $\mathrm{R}$ putamen & $\begin{array}{l}4.22 \pm \\
.07\end{array}$ & $\begin{array}{l}3.82 \pm \\
.08\end{array}$ & $\begin{array}{l}4.10 \pm \\
.08\end{array}$ & $\begin{array}{l}3.81 \pm \\
.07\end{array}$ & $\begin{array}{l}4.11 \\
\pm .08\end{array}$ & $\begin{array}{l}3.79 \pm \\
.08\end{array}$ & $5.77(6,146)$ & $<.0001$ & 0.17 & $\mathrm{HeM}>$ all female groups & $\begin{array}{l}\text { HeM }>\text { HeW } \\
\text { HoM }>\text { HeW } \\
(\mathrm{t}=3.716, \mathrm{p}<.001 ; \\
\mathrm{t}=2.570, \mathrm{p}=.011)\end{array}$ & $\begin{array}{l}\mathrm{HeM}>\mathrm{HeW}^{*} \\
\mathrm{HoM}>\mathrm{HeW} *\end{array}$ \\
\hline L hippocampus & $\begin{array}{l}3.42 \pm \\
.06\end{array}$ & $\begin{array}{l}3.15 \pm \\
.06\end{array}$ & $\begin{array}{l}3.32 \pm \\
.06\end{array}$ & $\begin{array}{l}3.09 \pm \\
.06\end{array}$ & $\begin{array}{l}3.32 \\
\pm .06\end{array}$ & $\begin{array}{l}3.07 \pm \\
.06\end{array}$ & $5.40(6,146)$ & $<.0001$ & 0.16 & $\mathrm{HeM}>$ all female groups & $\begin{array}{l}\mathbf{H e M}>\mathbf{H e W} \\
(\mathrm{t}=3.21, \mathrm{p}=.002)\end{array}$ & $\mathrm{HeM}>\mathrm{HeW}$ \\
\hline R hippocampus & $\begin{array}{l}3.72 \pm \\
.06\end{array}$ & $\begin{array}{l}3.48 \pm \\
.06\end{array}$ & $\begin{array}{l}3.62 \pm \\
.06\end{array}$ & $\begin{array}{l}3.35 \pm \\
.06\end{array}$ & $\begin{array}{l}3.62 \\
\pm .06\end{array}$ & $\begin{array}{l}3.39 \pm \\
.06\end{array}$ & $5.24(6,146)$ & $<.0001$ & 0.15 & $\begin{array}{l}\mathrm{HeM}>\mathrm{BiW} \& \mathrm{HoW} \\
\mathrm{BiM}>\mathrm{BiW} \\
\mathrm{HoW}>\mathrm{BiW}\end{array}$ & $\begin{array}{l}\begin{array}{l}\text { HeM }>\text { HeW } \\
(\mathrm{t}=2.75, \mathrm{p}=.007)\end{array}\end{array}$ & $\begin{array}{l}\mathrm{HeM}>\mathrm{HeW} \\
\mathrm{HoM}>\mathrm{HeW}\end{array}$ \\
\hline L amygdala & $\begin{array}{l}1.09 \pm \\
.02\end{array}$ & $\begin{array}{l}0.97 \pm \\
.02\end{array}$ & $\begin{array}{l}1.04 \pm \\
.02\end{array}$ & $\begin{array}{l}0.95 \pm \\
.02\end{array}$ & $\begin{array}{l}1.04 \\
\pm .02\end{array}$ & $\begin{array}{l}0.95 \pm \\
.02\end{array}$ & $7.38(6,146)$ & $<.0001$ & 0.23 & $\begin{array}{l}\mathrm{HeM}>\text { all female groups } \\
\mathrm{BiM}>\mathrm{BiW}, \mathrm{HoW} \\
\mathrm{HoM}>\mathrm{BiW}, \mathrm{HoW}\end{array}$ & $\begin{array}{l}\text { HeM }>\text { HeW } \\
\text { HoM }>\text { HeW } \\
(\mathrm{t}=4.10, \mathrm{p}<.0001 ; \\
\mathrm{t}=2.48, \mathrm{p}=.014)\end{array}$ & $\begin{array}{l}\mathrm{HeM}>\mathrm{HeW}^{*} \\
\mathrm{HoM}>\mathrm{HeW}^{*}\end{array}$ \\
\hline $\mathrm{R}$ amygdala & $\begin{array}{l}1.02 \pm \\
.02\end{array}$ & $\begin{array}{l}0.91 \pm \\
.02\end{array}$ & $\begin{array}{l}0.99 \pm \\
.02\end{array}$ & $\begin{array}{l}0.89 \pm \\
.02\end{array}$ & $\begin{array}{l}0.98 \\
\pm .02\end{array}$ & $\begin{array}{l}0.90 \pm \\
.02\end{array}$ & $7.33(6,146)$ & $<.0001$ & 0.20 & $\begin{array}{l}\mathrm{HeM}>\text { all female groups } \\
\mathrm{BiM}>\mathrm{BiW} \& \mathrm{HoW} \\
\mathrm{HoM}>\mathrm{BiW}\end{array}$ & $\begin{array}{l}\text { HeM }>\text { HeW } \\
\text { HoM }>\text { HeW } \\
(\mathrm{t}=3.87, \mathrm{p}<.001 \\
\mathrm{t}=2.39, \mathrm{p}=.018)\end{array}$ & $\begin{array}{l}\mathrm{HeM}>\mathrm{HeW}^{*} \\
\mathrm{HoM}>\mathrm{HeW}^{*}\end{array}$ \\
\hline L thalamus & $\begin{array}{l}6.17 \pm \\
.11\end{array}$ & $\begin{array}{l}5.54 \pm \\
.12\end{array}$ & $\begin{array}{l}6.12 \pm \\
.12\end{array}$ & $\begin{array}{l}5.49 \pm \\
.11\end{array}$ & $\begin{array}{l}5.97 \\
\pm .12\end{array}$ & $\begin{array}{l}5.50 \pm \\
.12\end{array}$ & $6.97(6,146)$ & $<.0001$ & 0.19 & $\begin{array}{l}\mathrm{HeM}>\text { all female groups } \\
\mathrm{BiM}>\text { all female groups }\end{array}$ & $\begin{array}{l}\text { HeM > HeW } \\
\text { HoM > HeW } \\
(\mathrm{t}=3.82, \mathrm{p}<.001 ; \\
\mathrm{t}=2.45, \mathrm{p}=.012)\end{array}$ & $\begin{array}{l}\mathrm{HeM}>\mathrm{HeW}^{*} \\
\mathrm{HeM}>\mathrm{HoM}^{*}\end{array}$ \\
\hline $\mathrm{R}$ thalamus & $\begin{array}{l}6.38 \pm \\
.12\end{array}$ & $\begin{array}{l}5.75 \pm \\
.12\end{array}$ & $\begin{array}{l}6.32 \pm \\
.12\end{array}$ & $\begin{array}{l}5.64 \pm \\
.12\end{array}$ & $\begin{array}{l}6.15 \\
\pm .12 \\
\end{array}$ & $\begin{array}{l}5.73 \pm \\
.12\end{array}$ & $6.95(6,146)$ & $<.0001$ & 0.19 & $\begin{array}{l}\mathrm{HeM}>\text { all female groups } \\
\mathrm{BiM}>\text { all female groups } \\
\mathrm{HoM}>\mathrm{BiW}\end{array}$ & $\begin{array}{l}\mathbf{H e M}>\mathbf{H e W} \\
(\mathrm{t}=3.79, \mathrm{p}<.001)\end{array}$ & $\begin{array}{l}\mathrm{HeM}>\mathrm{HeW}^{*} \\
\mathrm{HeM}>\mathrm{HoM}^{*}\end{array}$ \\
\hline L cerebellum & $\begin{array}{l}46.47 \\
\pm \\
.95 \\
\end{array}$ & $\begin{array}{l}43.36 \\
\pm .98\end{array}$ & $\begin{array}{l}45.09 \\
\pm \\
.98 \\
\end{array}$ & $\begin{array}{l}43.54 \pm \\
.96\end{array}$ & $\begin{array}{l}45.84 \\
\pm \\
.99 \\
\end{array}$ & $\begin{array}{l}40.94 \\
\pm \\
1.01 \\
\end{array}$ & $3.99(6,146)$ & .002 & 0.12 & $\begin{array}{l}\mathrm{HeM}>\mathrm{HoW} \\
\mathrm{HoM}>\mathrm{HoW}\end{array}$ & $\begin{array}{l}\mathrm{HeM}>\mathrm{HeW} \\
(\mathrm{t}=2.27, \mathrm{p}=.024)\end{array}$ & $\begin{array}{l}\mathrm{HeM}>\mathrm{HeW}^{*} \\
\mathrm{HoM}>\mathrm{HeW}^{*}\end{array}$ \\
\hline $\mathrm{R}$ cerebellum & $\begin{array}{l}47.40 \\
\pm .97\end{array}$ & $\begin{array}{l}43.89 \\
\pm .10\end{array}$ & $\begin{array}{l}46.28 \\
\pm .99\end{array}$ & $\begin{array}{l}44.15 \pm \\
.97\end{array}$ & $\begin{array}{l}47.42 \\
\pm \\
1.01\end{array}$ & $\begin{array}{l}42.08 \\
\pm \\
1.02\end{array}$ & $4.41(6,146)$ & $<.001$ & 0.13 & $\begin{array}{l}\mathrm{HoM}>\mathrm{HoW} \\
\mathrm{HeM}>\mathrm{HoW}\end{array}$ & $\begin{array}{l}\text { HeM > HeW } \\
\text { HoM }>\text { HeW } \\
(t=2.35, p=.012 \\
t=2.48, p=.014)\end{array}$ & $\begin{array}{l}\mathrm{HeM}>\mathrm{HeW}^{*} \\
\mathrm{HoM}>\mathrm{HeW}^{*}\end{array}$ \\
\hline $\begin{array}{l}\text { Summaries of } \\
\text { findings }\end{array}$ & & & & & & & & & & $\begin{array}{l}\text { Summary of exploratory } \\
\text { ANCOVAs: Subcortical volumes } \\
\text { differences in our exploratory } \\
\text { ANCOVAs were in all in an expected } \\
\text { male > female direction, consistent } \\
\text { with research on sex differences. No } \\
\text { differences between heterosexual, } \\
\text { bisexual, and homosexual women } \\
\end{array}$ & $\begin{array}{l}\text { Summary of attempted } \\
\text { replication: All replicated } \\
\text { differences from Abé, } \\
\text { Johansson, Allzén, \& Savic } \\
\text { 2014 were in a male > } \\
\text { female direction. However, } \\
\text { the few differences found } \\
\text { between heterosexual and } \\
\end{array}$ & $\begin{array}{l}\text { Summary of study being } \\
\text { replicated: Most } \\
\text { subcortical differences } \\
\text { found in this study were in } \\
\text { an expected male }>\text { female } \\
\text { direction. However, there } \\
\text { were two differences } \\
\text { between homosexual and } \\
\end{array}$ \\
\hline
\end{tabular}




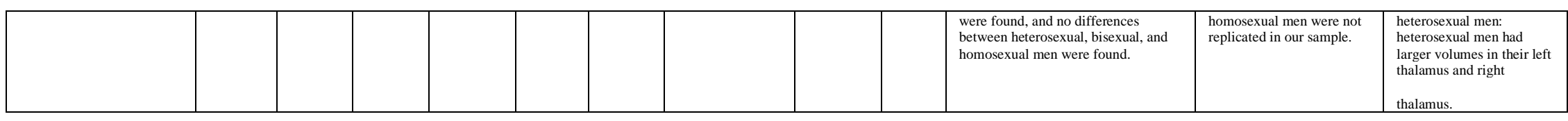

Table 4 contains descriptive statistics for raw subcortical volume measures along with exploratory ANCOVAs comparing six sex/orientation groups (HeM, $\mathrm{HeW}$, BiM, BiW, HoM, and HoW).All tests include participant age as a covariate. Descriptive statistics show least square means \pm standard error. Exploratory ANCOVAs reveal a number of group differences, all in a male $>$ female direction (confirmed using Tukey's HSD post hoc tests). The table also shows an attempted replication of findings from Abé et al. 2014 using planned contrasts. HeM = heterosexual males, HeW = heterosexual females, BiM = bisexual males, BiW = bisexual females, HoM = homosexual males, HoW = homosexual females. 
Table 5: Differences in Subcortical Volumes (Corrected for TIV); Attempted Replication of Manzouri \& Savic 2018

\begin{tabular}{|c|c|c|c|c|c|c|c|c|c|c|c|c|}
\hline & $\begin{array}{l}H e M \\
N=26\end{array}$ & $\begin{array}{l}\mathrm{HeW} \\
\mathrm{N}=24\end{array}$ & $\begin{array}{l}B i M \\
N=28\end{array}$ & $\begin{array}{l}B i W \\
N=26\end{array}$ & $\begin{array}{l}H o M \\
N=24\end{array}$ & $\begin{array}{l}H o W \\
N=24\end{array}$ & $F(d f)$ & $p$-value & $\eta p^{2}$ & $\begin{array}{l}\text { Differences in } \\
\text { present sample } \\
\text { (ANCOVAs) } \\
\\
\text { Tests include all } \\
\text { groups (HeW, } \\
\text { HeM, BiW, } \\
\text { BiM, HeM, } \\
\text { HoM) }\end{array}$ & $\begin{array}{l}\text { Follow-up planned } \\
\text { contrasts: attempted } \\
\text { replication of } \\
\text { Manzouri \& Savic, } \\
2018 \\
\text { Tests include HeW, } \\
\text { HeM, HoW, \& } \\
\text { HoM) }\end{array}$ & $\begin{array}{l}\text { Findings present in } \\
\text { Manzouri \& Savic, } \\
2018 \\
\text { Tests include: HeW, } \\
\text { HeM, HoW, \& HoM }\end{array}$ \\
\hline \multicolumn{13}{|c|}{ Structural volume } \\
\hline L hippocampus & $\begin{array}{l}3.25 \pm \\
.05\end{array}$ & $\begin{array}{l}3.30 \pm \\
.05\end{array}$ & $\begin{array}{l}3.17 \pm \\
.05\end{array}$ & $\begin{array}{l}3.27 \pm \\
.05\end{array}$ & $\begin{array}{l}3.22 \pm \\
.05\end{array}$ & $\begin{array}{l}3.19 \pm \\
.05\end{array}$ & $1.07(7,145)$ & 0.38 & .036 & No differences & No differences & $\begin{array}{l}\text { HeW \& HoW > } \\
\text { HeM \& HoM }\end{array}$ \\
\hline R hippocampus & $\begin{array}{l}3.55 \pm \\
.05\end{array}$ & $\begin{array}{l}3.62 \pm \\
.05\end{array}$ & $\begin{array}{l}3.48 \pm \\
.05\end{array}$ & $\begin{array}{l}3.52 \pm \\
.05\end{array}$ & $\begin{array}{l}3.52 \pm \\
.05\end{array}$ & $\begin{array}{l}3.50 \pm \\
.05\end{array}$ & $0.96(7,145)$ & 0.445 & .032 & No differences & No differences & $\begin{array}{l}\text { HeW \& HoW > } \\
\text { HeM \& HoM }\end{array}$ \\
\hline L caudate & $\begin{array}{l}2.94 \pm \\
.06\end{array}$ & $\begin{array}{l}3.08 \pm \\
.06\end{array}$ & $\begin{array}{l}2.92 \pm \\
.06\end{array}$ & $\begin{array}{l}3.16 \pm \\
.06\end{array}$ & $\begin{array}{l}2.91 \pm \\
.06\end{array}$ & $\begin{array}{l}3.04 \pm \\
.06\end{array}$ & $1.95(7,145)$ & 0.09 & .063 & No differences & No differences & $\begin{array}{l}\mathrm{HeW} \& \mathrm{HoW}>\mathrm{HeM} \\
\& \mathrm{HoM}\end{array}$ \\
\hline R caudate & $\begin{array}{l}2.90 \pm \\
.06\end{array}$ & $\begin{array}{l}3.13 \pm \\
.06\end{array}$ & $\begin{array}{l}2.94 \pm \\
.06\end{array}$ & $\begin{array}{l}3.20 \pm \\
.06\end{array}$ & $\begin{array}{l}2.94 \pm \\
.06\end{array}$ & $\begin{array}{l}3.04 \pm \\
.06\end{array}$ & $2.74(7,145)$ & 0.022 & .086 & $\mathrm{BiW}>\mathrm{HeM}$ & $\begin{array}{l}\mathrm{HeW}>\mathrm{HeM} \& \mathrm{HoM} \\
(\mathrm{t}=2.495 \mathrm{p}=.012)\end{array}$ & $\begin{array}{l}\text { HeW \& HoW > } \\
\text { HeM \& HoM }\end{array}$ \\
\hline
\end{tabular}

Additional areas tested by Manzouri and Savic included the right putamen, left putamen, right amygdala, and left amygdala. These areas did not show any group differences in the analyses performed by Manzouri and Svic, and so we did not include them in these replication attempts.

Table 5 contains descriptive statistics for subcortical volumes along with results of exploratory ANCOVAs comparing six sex/orientation groups (HeW, BiW, HoW, HeM, BiM, HoM), as well as planned contrasts attempting to replicate past work (Manzouri \& Savic, 2018). All tests include participant age and total intracranial volume (TIV) as covariates. Descriptive statistics show least square means \pm standard error. Exploratory ANCOVAs show one difference based on Tukey's HSD post hoc tests: bisexual women had larger TIV-corrected right caudate volumes than heterosexual men. Follow-up planned contrasts replicate one sex difference from Manzouri and Savic: heterosexual women have larger TIV-corrected right caudate volumes than both heterosexual men and homosexual men.

$\mathrm{HeM}=$ heterosexual males, $\mathrm{HeW}=$ heterosexual females, $\mathrm{BiM}=$ bisexual males, $\mathrm{BiW}=$ bisexual females, $\mathrm{HoM}=$ homosexual males, HoW = homosexual females. 
Table 6. Differences in Regional Cortical Thickness; Attempted Replication of Abé, Johansson, Allzén, \& Savic 2014

\begin{tabular}{|c|c|c|c|c|c|c|c|c|c|c|c|c|}
\hline & $\begin{array}{l}H e M \\
N=26\end{array}$ & $\begin{array}{l}\mathrm{HeW} \\
\mathrm{N}=25\end{array}$ & $\begin{array}{l}B i M \\
N=28\end{array}$ & $\begin{array}{l}B i W \\
N=26\end{array}$ & $\begin{array}{l}H o M \\
N=24\end{array}$ & $\begin{array}{l}H o W \\
N=24\end{array}$ & $F(d f)$ & $p$-value & $\eta p^{2}$ & $\begin{array}{l}\text { Differences } \\
\text { in } \\
\text { present } \\
\text { sample: } \\
\text { ANCOVAs } \\
\\
\text { (all groups) }\end{array}$ & $\begin{array}{l}\text { Differences } \\
\text { in present } \\
\text { sample: } \\
\text { follow-up } \\
\text { planned } \\
\text { contrasts } \\
\text { (HeM, } \\
\text { HeW, and } \\
\text { HoM) }\end{array}$ & $\begin{array}{l}\text { Abé, } \\
\text { Johansson, } \\
\text { Allzén, \& } \\
\text { Savic } 2014 \\
\\
\begin{array}{l}\text { (HeM, HeW, } \\
\text { and HoM) }\end{array}\end{array}$ \\
\hline \multicolumn{13}{|l|}{ Cortical thickness } \\
\hline L middle temporal & $\begin{array}{l}3.34 \pm \\
.03\end{array}$ & $\begin{array}{l}3.33 \pm \\
.03\end{array}$ & $\begin{array}{l}3.31 \pm \\
.03\end{array}$ & $\begin{array}{l}3.34 \pm \\
.03\end{array}$ & $\begin{array}{l}3.37 \pm \\
.03\end{array}$ & $\begin{array}{l}3.29 \pm \\
.03\end{array}$ & $0.76(6,146)$ & 0.577 & 0.025 & $\begin{array}{l}\text { No } \\
\text { differences }\end{array}$ & $\begin{array}{l}\text { No } \\
\text { differences }\end{array}$ & $\begin{array}{l}\mathrm{HeM}>\mathrm{HeW} \\
\mathrm{HoM}>\mathrm{HeW}^{*}\end{array}$ \\
\hline L superior temporal & $\begin{array}{l}3.17 \pm \\
.03\end{array}$ & $\begin{array}{l}3.14 \pm \\
.03\end{array}$ & $\begin{array}{l}3.09 \pm \\
.03\end{array}$ & $\begin{array}{l}3.12 \pm \\
.03\end{array}$ & $\begin{array}{l}3.11 \pm \\
.03\end{array}$ & $\begin{array}{l}3.09 \pm \\
.03\end{array}$ & $1.02(6,146)$ & 0.408 & 0.034 & $\begin{array}{l}\text { No } \\
\text { differences }\end{array}$ & $\begin{array}{l}\text { No } \\
\text { differences }\end{array}$ & $\begin{array}{l}\mathrm{HeM}>\mathrm{HeW} \\
\mathrm{HoM}>\mathrm{HeW}\end{array}$ \\
\hline $\mathrm{R}$ inferior temporal & $\begin{array}{l}3.12 \pm \\
.03\end{array}$ & $\begin{array}{l}3.12 \pm \\
.04 \\
\end{array}$ & $\begin{array}{l}3.06 \pm \\
.04 \\
\end{array}$ & $\begin{array}{l}3.12 \pm \\
.04\end{array}$ & $\begin{array}{l}3.08 \pm \\
.04\end{array}$ & $\begin{array}{l}3.06 \pm \\
.04\end{array}$ & $0.60(6,146)$ & 0.699 & 0.020 & $\begin{array}{l}\text { No } \\
\text { differences }\end{array}$ & $\begin{array}{l}\text { No } \\
\text { differences }\end{array}$ & $\mathrm{HeM}>\mathrm{HoM}$ \\
\hline $\mathrm{R}$ lateral orbitofrontal & $\begin{array}{l}3.26 \pm \\
.03\end{array}$ & $\begin{array}{l}3.29 \pm \\
.03\end{array}$ & $\begin{array}{l}3.26 \pm \\
.03\end{array}$ & $\begin{array}{l}3.28 \pm \\
.03\end{array}$ & $\begin{array}{l}3.25 \pm \\
.03\end{array}$ & $\begin{array}{l}3.19 \pm \\
.03\end{array}$ & $0.98(6,146)$ & 0.432 & 0.032 & $\begin{array}{l}\text { No } \\
\text { differences }\end{array}$ & $\begin{array}{l}\text { No } \\
\text { differences }\end{array}$ & $\begin{array}{l}\mathrm{HeM}>\mathrm{HeW} \\
\mathrm{HeM}>\mathrm{HoM}\end{array}$ \\
\hline $\mathrm{R}$ pars triangularis & $\begin{array}{l}2.99 \pm \\
.03 \\
\end{array}$ & $\begin{array}{l}3.02 \pm \\
.03 \\
\end{array}$ & $\begin{array}{l}3.01 \pm \\
.03 \\
\end{array}$ & $\begin{array}{l}3.01 \pm \\
.03 \\
\end{array}$ & $\begin{array}{l}2.97 \pm \\
.03\end{array}$ & $\begin{array}{l}3.00 \pm \\
.03\end{array}$ & $0.89(6,146)$ & 0.335 & 0.011 & $\begin{array}{l}\text { No } \\
\text { differences }\end{array}$ & $\begin{array}{l}\text { No } \\
\text { differences }\end{array}$ & $\begin{array}{l}\mathrm{HeW}>\mathrm{HoM} \\
\mathrm{HeM}>\mathrm{HoM}^{*}\end{array}$ \\
\hline $\mathrm{R}$ lingual & $\begin{array}{l}2.18 \pm \\
.03\end{array}$ & $\begin{array}{l}2.24 \pm \\
.03\end{array}$ & $\begin{array}{l}2.19 \pm \\
.03\end{array}$ & $\begin{array}{l}2.22 \pm \\
.03\end{array}$ & $\begin{array}{l}2.19 \pm \\
.03\end{array}$ & $\begin{array}{l}2.13 \pm \\
.03\end{array}$ & $1.92(6,146)$ & 0.094 & 0.062 & $\begin{array}{l}\text { No } \\
\text { differences }\end{array}$ & $\begin{array}{l}\text { No } \\
\text { differences }\end{array}$ & $\begin{array}{l}\mathrm{HeM}>\mathrm{HeW}^{*} \\
\mathrm{HeM}>\mathrm{HoM}^{*}\end{array}$ \\
\hline $\mathrm{R}$ cuneus & $\begin{array}{l}2.17 \pm \\
.03 \\
\end{array}$ & $\begin{array}{l}2.20 \pm \\
.03 \\
\end{array}$ & $\begin{array}{l}2.20 \pm \\
.03 \\
\end{array}$ & $\begin{array}{l}2.18 \pm \\
.03 \\
\end{array}$ & $\begin{array}{l}2.17 \pm \\
.03\end{array}$ & $\begin{array}{l}2.14 \pm \\
.03 \\
\end{array}$ & $0.47(6,146)$ & 0.798 & 0.016 & $\begin{array}{l}\text { No } \\
\text { differences }\end{array}$ & $\begin{array}{l}\text { No } \\
\text { differences }\end{array}$ & $\begin{array}{l}\mathrm{HeM}>\mathrm{HeW} \\
\mathrm{HeM}>\mathrm{HoM}^{*}\end{array}$ \\
\hline R pericalcarine & $\begin{array}{l}1.98 \pm \\
.03 \\
\end{array}$ & $\begin{array}{l}2.03 \pm \\
.03 \\
\end{array}$ & $\begin{array}{l}2.01 \pm \\
.03 \\
\end{array}$ & $\begin{array}{l}2.07 \pm \\
.03 \\
\end{array}$ & $\begin{array}{l}2.03 \pm \\
.03\end{array}$ & $\begin{array}{l}1.95 \pm \\
.03 \\
\end{array}$ & $1.68(1,146)$ & 0.143 & 0.054 & $\begin{array}{l}\text { No } \\
\text { differences }\end{array}$ & $\begin{array}{l}\text { No } \\
\text { differences }\end{array}$ & $\begin{array}{l}\mathrm{HeM}>\mathrm{HeW}^{*} \\
\mathrm{HeM}>\mathrm{HoM}^{*}\end{array}$ \\
\hline
\end{tabular}

Table 6 contains descriptive statistics for cortical thickness measures along with exploratory ANCOVAs comparing six sex/orientation groups (HeM, HeW, BiM, $\mathrm{BiW}$, HoM, and HoW). All tests include participant age as a covariate. Descriptive statistics show least square means \pm standard error for mm in thickness. The table also shows an attempted replication of findings from Abé et al. 2014 using planned contrasts. The last column shows patterns of findings from Abé et al. 2014. In this column, an asterisk * indicates the results that survived multiple comparisons in Abé et al. In addition to these significant restuls, we also included differences from the study that did not surive multiple comparisons. No differences were found that were in line with either significant patterns in Abé et al, or with trending patterns that failed to survive comparison for multiple corrections. HeM = heterosexual males, HeW = heterosexual females, BiM = bisexual males, BiW = bisexual females, HoM = homosexual males, HoW = homosexual females. 
Table 7. Relative Gray Matter Volume Differences Across the Whole Brain (Corrected for Total Intracranial Volume)

\begin{tabular}{|c|c|c|c|c|c|}
\hline \multicolumn{2}{|c|}{ Female vs. Male Participants } & & & & \\
\hline \multicolumn{6}{|c|}{ Heterosexual Women > Heterosexual Men } \\
\hline Right/Left & Region & $\begin{array}{l}\text { Brodmann } \\
\text { area }\end{array}$ & $\begin{array}{l}M N I \\
\text { coordinates }\end{array}$ & $\begin{array}{l}\text { \# of } \\
\text { voxels }\end{array}$ & peak $T$ \\
\hline $\mathrm{L}$ & superior frontal gyrus & 8 & -102650 & 5 & 4.82 \\
\hline \multicolumn{6}{|c|}{ No results for Heterosexual Men > Heterosexual Women } \\
\hline \multicolumn{6}{|c|}{ Female Participants } \\
\hline \multicolumn{6}{|c|}{ Heterosexual Women > Homosexual Women } \\
\hline Right/Left & Region & $\begin{array}{l}\text { Brodmann's } \\
\text { area }\end{array}$ & $\begin{array}{l}\text { MNI } \\
\text { coordinates }\end{array}$ & $\begin{array}{l}\text { \# of } \\
\text { voxels }\end{array}$ & peak $T$ \\
\hline $\mathrm{R}$ & angular gyrus & 39,40 & $50-4642$ & 2 & 4.76 \\
\hline \multicolumn{6}{|c|}{ Heterosexual Women > Bisexual Women } \\
\hline $\mathrm{R}$ & olfactory tubercule & $\mathrm{n} / \mathrm{a}$ & $109-24$ & 19 & 4.95 \\
\hline \multicolumn{6}{|c|}{ Bisexual Women > Homosexual Women } \\
\hline $\mathrm{L}$ & supramarginal gyrus & 40,39 & $-45-4234$ & 3 & 4.74 \\
\hline \multicolumn{6}{|c|}{$\begin{array}{l}\text { No significant differences for Homosexual > Heterosexual } \\
\text { women, Bisexual > Heterosexual women, or Homosexual > } \\
\text { Bisexual women. }\end{array}$} \\
\hline \multicolumn{6}{|c|}{ Male Participants } \\
\hline $\begin{array}{l}\text { No signifi } \\
\text { men (eithe } \\
\text { (either dire } \\
\text { direction). }\end{array}$ & $\begin{array}{l}\text { ant differences for Heterosexual vs. Homosexual } \\
\text { direction), Heterosexual vs. Bisexual men } \\
\text { tion), or Bisexual vs. Homosexual men (either }\end{array}$ & & & & \\
\hline
\end{tabular}

Results of contrasts performed on the whole-brain level with $\mathrm{p}<0.05$ FWE correction and a voxel threshold of 2 .

All contrasts are corrected for participant age and total intracranial volume (TIV). $\mathrm{L}=$ left, $\mathrm{R}=$ right,

$\mathrm{BA}=$ Brodmann area. Coordinates are in MNI space. 
Table 8. Cortical Thickness Differences Across the Whole Brain

\begin{tabular}{|c|c|c|c|c|c|}
\hline \multicolumn{2}{|c|}{ Female vs. Male Participants } & & & & \\
\hline \multicolumn{6}{|c|}{ Heterosexual Women > Heterosexual Men } \\
\hline Right/Left & Region & $\begin{array}{l}\text { Brodmann } \\
\text { area }\end{array}$ & $\begin{array}{l}\text { MNI } \\
\text { coordinates }\end{array}$ & $\begin{array}{l}\text { \# of } \\
\text { voxels }\end{array}$ & peak $T$ \\
\hline $\mathrm{L}$ & superior frontal gyrus, medial premotor cortex & 6 & -13959 & 38 & 4.47 \\
\hline \multicolumn{6}{|c|}{$\begin{array}{l}\text { No significant differences for for Heterosexual Men > } \\
\text { Heterosexual Women. }\end{array}$} \\
\hline \multicolumn{6}{|c|}{ Female Participants } \\
\hline \multicolumn{6}{|c|}{ Bisexual Women > Homosexual Women } \\
\hline Right/Left & Region & $\begin{array}{l}\text { Brodmann } \\
\text { area }\end{array}$ & $\begin{array}{l}\text { MNI } \\
\text { coordinates }\end{array}$ & $\begin{array}{l}\text { \# of } \\
\text { voxels }\end{array}$ & peak $T$ \\
\hline $\mathrm{R}$ & anterior insula & 13 & $3516-6$ & 35 & 4.42 \\
\hline \multicolumn{6}{|c|}{$\begin{array}{l}\text { No significant differences for Homosexual > Bisexual } \\
\text { women, Heterosexual vs. Homosexual women (either } \\
\text { direction), or Bisexual vs. Heterosexual women (either } \\
\text { direction). }\end{array}$} \\
\hline \multicolumn{6}{|c|}{ Male Participants } \\
\hline $\begin{array}{l}\text { No signific } \\
\text { men (eithe } \\
\text { (either dire } \\
\text { direction). }\end{array}$ & $\begin{array}{l}\text { ant differences for Heterosexual vs. Homosexual } \\
\text { direction), Heterosexual vs. Bisexual men } \\
\text { tion), or Bisexual vs. Homosexual men (either }\end{array}$ & & & & \\
\hline
\end{tabular}

Results of contrasts performed on the whole-brain level with $p<0.05$ FWE correction and a voxel threshold of 2. All contrasts are corrected for participant age, but not total intracranial volume (TIV). $\mathrm{L}=$ left, $\mathrm{R}=$ right, $\mathrm{BA}=$ Brodmann area. Coordinates are in MNI space. 


\section{APPENDIX}

Appendix Table 1. Raw Gray Matter Volume Differences Across the Whole Brain, Between Sex

WITHOUT BRAIN VOLUME CORRECTION

Female vs. Male Participants

Heterosexual Men > Heterosexual Women

\begin{tabular}{|c|c|c|c|c|c|}
\hline Right/Left & Region & $\begin{array}{l}\text { Brodmann's } \\
\text { area }\end{array}$ & $\begin{array}{l}\text { MNI } \\
\text { coordinates }\end{array}$ & \# of voxels & peak $T$ \\
\hline $\mathrm{L} / \mathrm{R}$ & $\begin{array}{l}\text { ventral striatum }(\mathrm{R} / \mathrm{L}) \text {, caudate nucleus }(\mathrm{R} / \mathrm{L}) \text {, olfactory } \\
\text { cortex }(\mathrm{L}) \text {, claustrum }(\mathrm{L})\end{array}$ & N/A & $-82-8$ & 1797 & 6.464 \\
\hline $\mathrm{L} / \mathrm{R}$ & caudate $(\mathrm{R} / \mathrm{L}$, septum pellucidum $(\mathrm{R} / \mathrm{L})$ & N/A & $-6-18-3$ & & 5.279 \\
\hline $\mathrm{L}$ & amygdala (L), parahippocampal gyrus (L) & BA 53, BA 36 & $-320-26$ & & 5.158 \\
\hline $\mathrm{L}$ & anterior hipppocampus, parahippocampal gyrus & BA 54, 36 & $-17-9-30$ & 518 & 5.718 \\
\hline $\mathrm{R}$ & parahippocampal gyrus & BA 36 & $27-15-27$ & 149 & 5.604 \\
\hline $\mathrm{R}$ & fusiform gyrus & BA 37 & $39-68-20$ & 185 & 5.600 \\
\hline $\mathrm{L} / \mathrm{R}$ & cerebellar vermis (10) & N/A & $3-51-24$ & 837 & 5.578 \\
\hline $\mathrm{L}$ & visual cortex (V2), inferior occipital lobe & BA 18 & $-14-77-11$ & & 5.281 \\
\hline $\begin{array}{ll}\mathrm{L} \\
\end{array}$ & middle temporal gyrus, posterior temporal pole & BA 38 & $-440-24$ & 117 & 5.566 \\
\hline $\mathrm{L}$ & thalamus (pulvinar) & BA 50 & $-20-2715$ & 61 & 5.478 \\
\hline $\mathrm{L}$ & lingual gyrus & BA 18 & $-12-800$ & 48 & 5.471 \\
\hline $\mathrm{R}$ & occipitotemporal junction, inferior middle temporal gyrus & BA 37 & $68-51-2$ & 120 & 5.437 \\
\hline $\mathrm{R}$ & thalamus & BA 50 & $8-18-3$ & 37 & 5.370 \\
\hline $\mathrm{R}$ & inferior temporal gyrus & BA 37 & $65-39-23$ & 253 & 5.317 \\
\hline $\mathrm{L}$ & cerebellum (crus 1) & N/A & $-21-92-24$ & 58 & 5.224 \\
\hline $\mathrm{R}$ & calcarine gyrus & BA 18 & $21-956$ & 63 & 5.217 \\
\hline $\mathrm{L}$ & posterior parahippocampal gyrus, lingual gyrus & BA 36, BA 18 & $-15-41-3$ & 229 & 5.201 \\
\hline $\begin{array}{ll}\mathrm{L} \\
\end{array}$ & ventral temporal cortex & BA 20 & $-44-33-32$ & 166 & 5.192 \\
\hline $\mathrm{R}$ & pars orbitalis & BA 47 & $3036-23$ & 20 & 5.190 \\
\hline $\mathrm{R}$ & middle temporal gyrus & BA 22 & $71-322$ & 100 & 5.190 \\
\hline $\mathrm{L}$ & premotor cortex & BA 6 & $-12-1581$ & 32 & 5.148 \\
\hline
\end{tabular}




\begin{tabular}{|c|c|c|c|c|c|}
\hline $\mathrm{R}$ & fusiform gyrus & BA 37 & $42-29-32$ & 127 & 5.105 \\
\hline $\mathrm{L}$ & superior temporal gyrus & BA 22 & $-53-9-3$ & 116 & 5.091 \\
\hline $\mathrm{L}$ & pars orbitalis & BA 47 & $-3229-9$ & 65 & 5.066 \\
\hline $\mathrm{L}$ & anterior insula & BA 13 & -23240 & 15 & 4.974 \\
\hline $\mathrm{R}$ & cerebellum (VI), visual cortex & BA 19 & $24-74-15$ & 25 & 4.894 \\
\hline $\mathrm{R}$ & amygdala & BA 53 & $29-5-12$ & 54 & 4.836 \\
\hline $\mathrm{R}$ & pallidum & N/A & $18-39$ & 6 & 4.810 \\
\hline $\mathrm{L}$ & middle temporal gyrus & BA 21 & $-56-23-15$ & 5 & 4.801 \\
\hline $\mathrm{L}$ & precuneus & BA 7 & $-8-4853$ & 25 & 4.793 \\
\hline $\begin{array}{l}\mathrm{L} \\
\mathrm{n}\end{array}$ & lateral orbitofrontal cortex & BA 47 & $-3032-24$ & 16 & 4.779 \\
\hline $\mathrm{L}$ & cerebellar vermis (4/5) & N/A & $-2-575$ & 2 & 4.758 \\
\hline $\mathrm{L}$ & inferior temporal gyrus & BA 20 & $-50-29-20$ & 6 & 4.717 \\
\hline $\mathrm{L}$ & lingual gyrus & BA 18 & $-14-720$ & 3 & 4.713 \\
\hline $\mathrm{R}$ & inferior temporal gyrus & BA 37 & $51-48-17$ & 5 & 4.699 \\
\hline $\mathrm{L}$ & calcarine gyrus & BA 17 & $-3-6512$ & 3 & 4.695 \\
\hline $\begin{array}{ll}\mathrm{L} \\
\end{array}$ & pallidum & N/A & $-18-89$ & 3 & 4.687 \\
\hline \multicolumn{6}{|c|}{ No results for Heterosexual Women > Heterosexual Men } \\
\hline \multicolumn{2}{|c|}{ Female Participants } & & & & \\
\hline \multicolumn{2}{|c|}{$\begin{array}{l}\text { No results for Heterosexual vs. Homosexual women (either direction), } \\
\text { Heterosexual vs. Bisexual women (either direction), or Bisexual vs. } \\
\text { Homosexual women (either direction). }\end{array}$} & & & & \\
\hline \multicolumn{2}{|c|}{ Male Participants } & & & & \\
\hline & $\begin{array}{l}\text { terosexual vs. Homosexual men (either direction), } \\
\text { Bisexual men (either direction), or Homosexual > Bisexual }\end{array}$ & & & & \\
\hline
\end{tabular}

Results of contrasts performed on the whole brain level with $\mathrm{p}<0.05$ FWE correction and a voxel threshold of 2 . All contrasts are corrected for participant age but not total intracranial volume (TIV). $\mathrm{L}=$ left, $\mathrm{R}=$ right, $\mathrm{BA}=$ Brodmann area. Coordinates are in MNI space. 
Appendix Figure 1a

- Heterosexual Women vs. • Heterosexual Men

Corrected for total brain volume

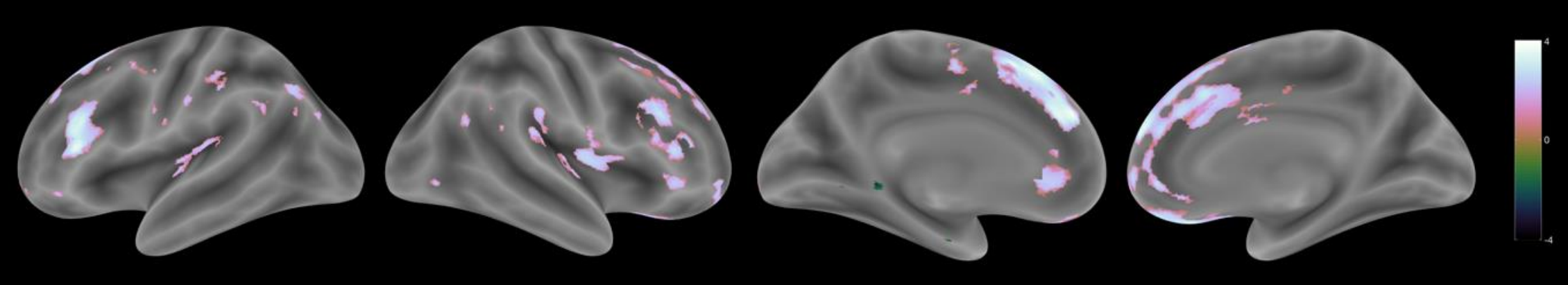

Not corrected for total brain volume

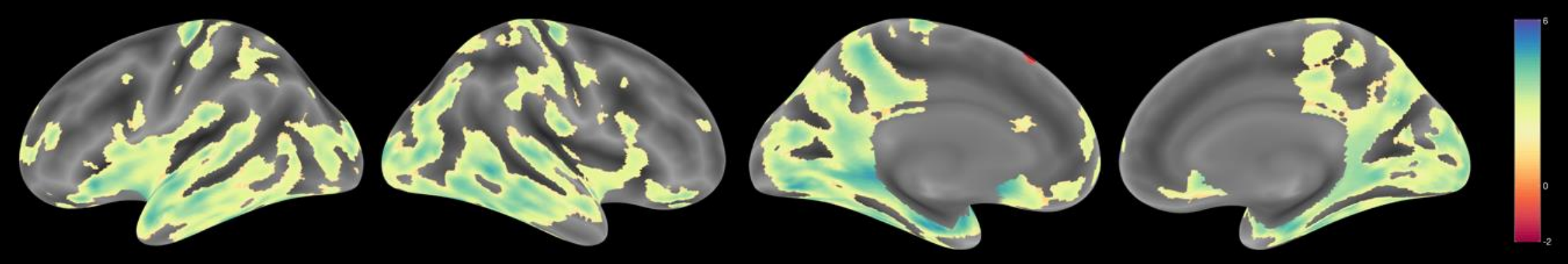




\section{Appendix Figure 1b}

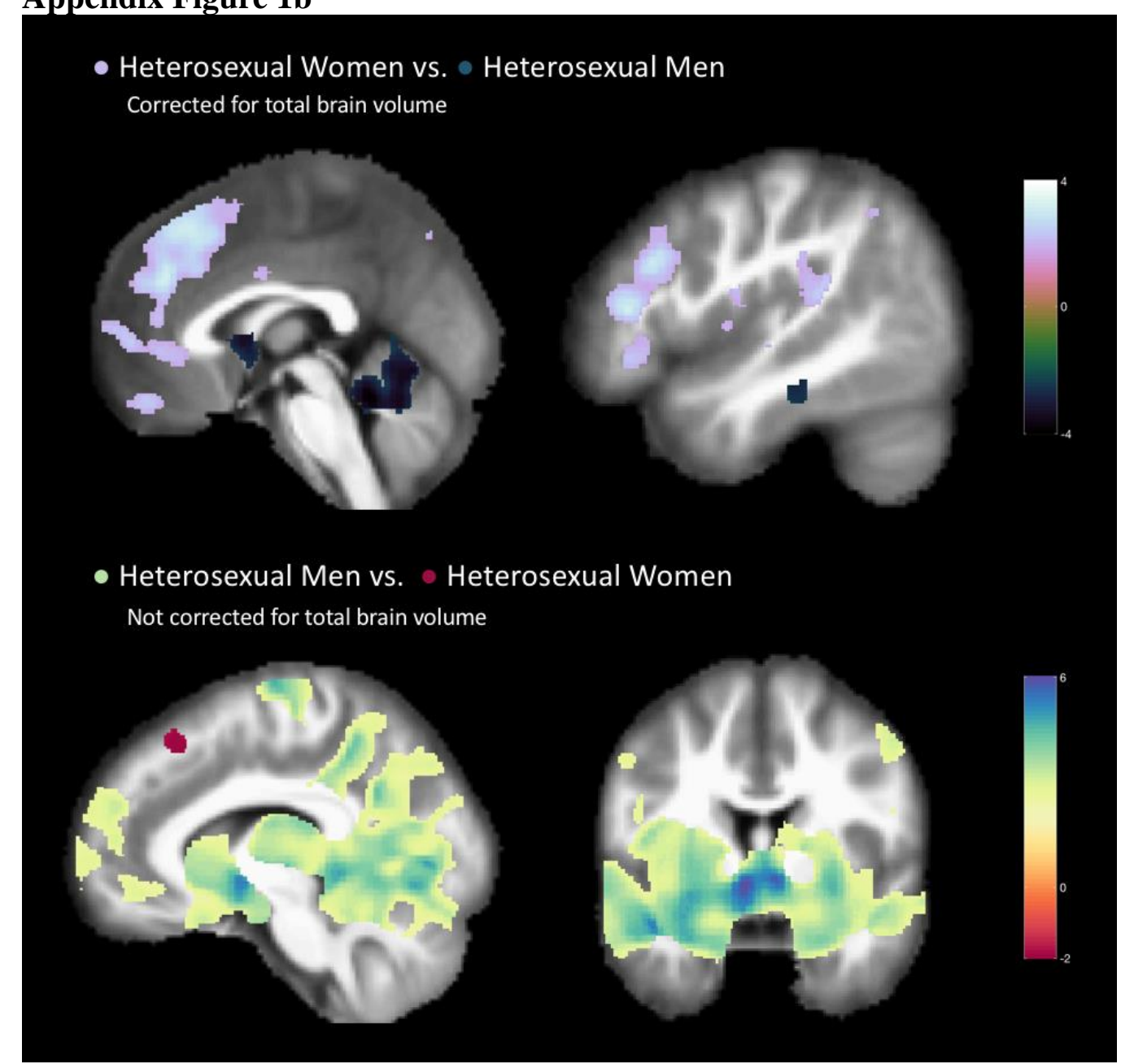

Figures 1a and 1b: Non-significant maps of comparisons between heterosexual men and heterosexual women in terms of gray matter volume. The top row of each figure shows differences adjusted for both total intracranial volume and age, and the bottom row shows differences adjusted only for age. All panels show comparisons obtained with an uncorrected threshold of $\mathrm{p}<.01$ and with a voxel cutoff of $\mathrm{k}=5$. Due to the lack of statistical correction, these maps should not be considered to represent significant results. 
Appendix Figure 2a

- Heterosexual Women vs. • Homosexual Women

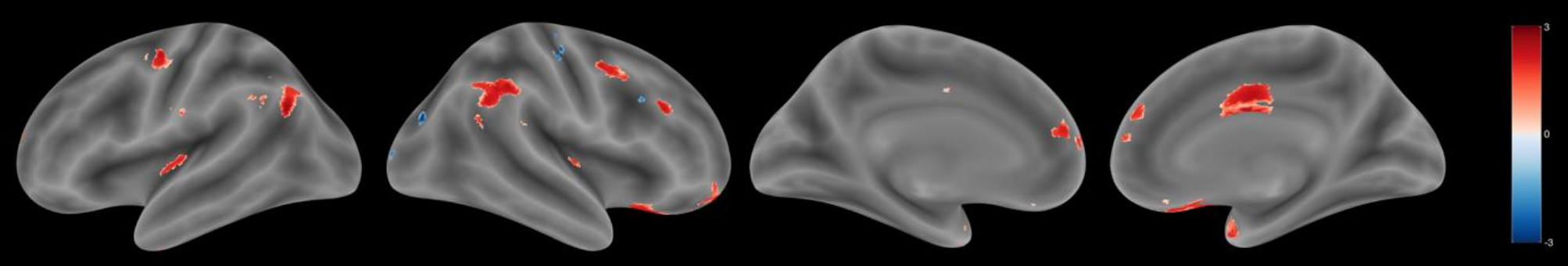

- Bisexual Women vs. • Homosexual Women

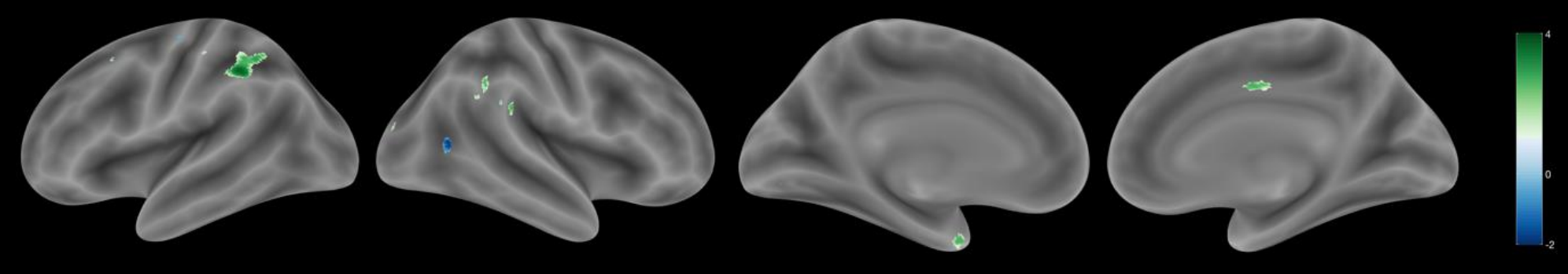

- Bisexual Women vs. • Heterosexual Women

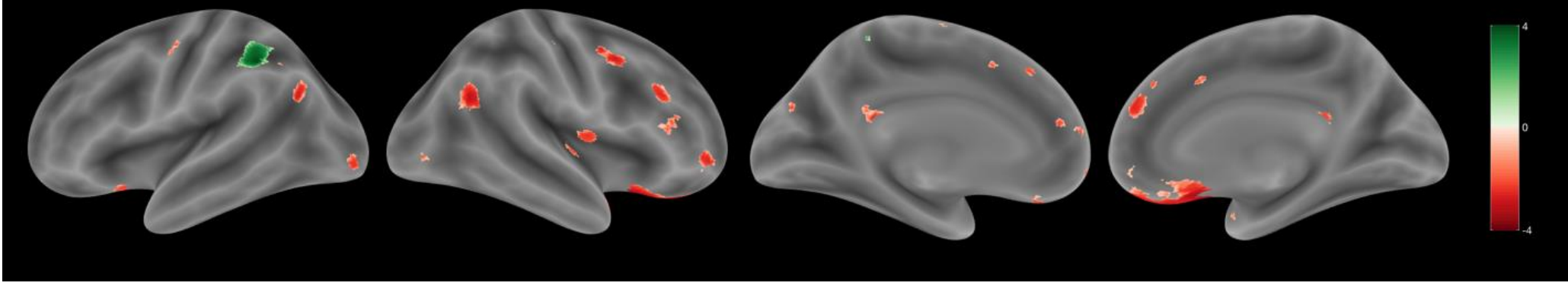




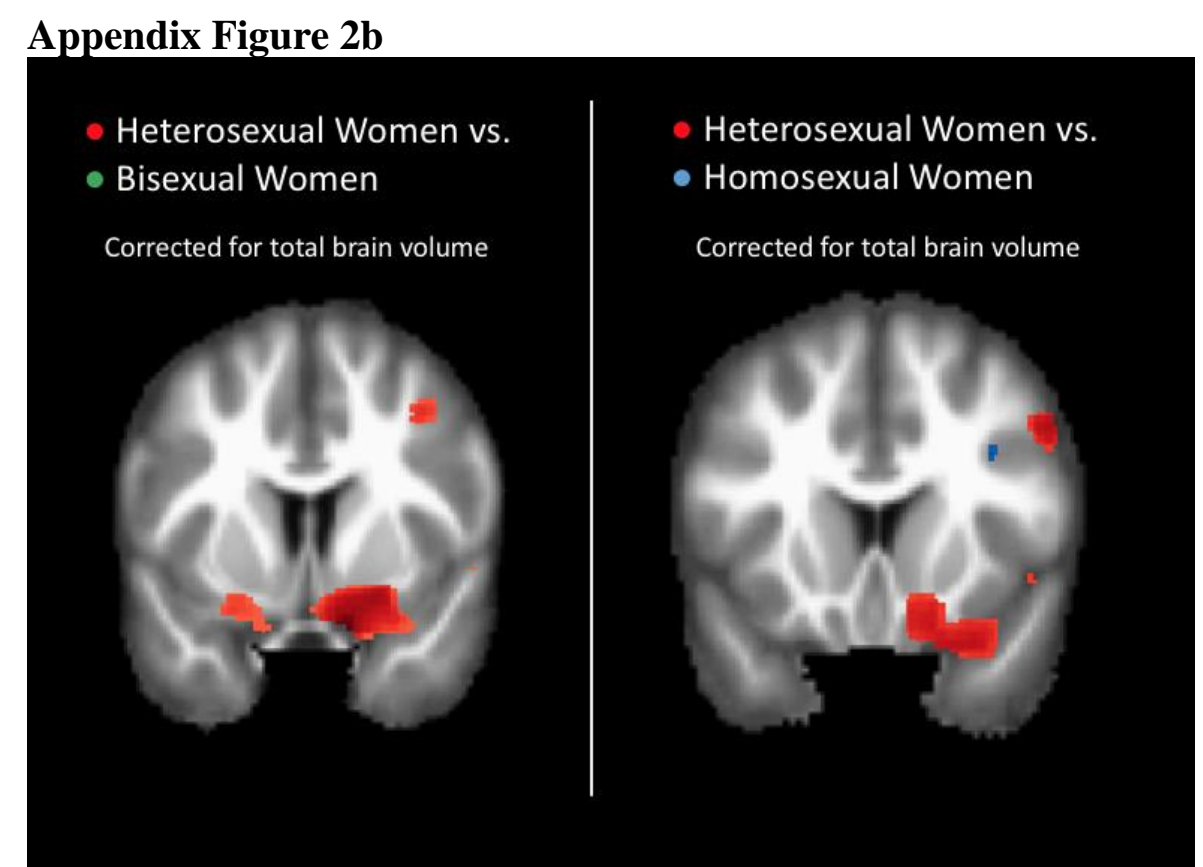

$2 \mathrm{a}$ and $2 \mathrm{~b}$. Non-significant comparisons of gray matter volume between female orientation groups (adjusted for age and total intracranial volume). All panels show results obtained with an uncorrected threshold of $\mathrm{p}<.01$ with a voxel cutoff of $\mathrm{k}=5$. Due to the lack of statistical correction, these maps should not be considered to represent significant results. Due to the relatively small variability of brain volume within sex (as opposed to between sex), similar patterns emerge for within-sex orientation comparisons regardless of brain volume correction. Figure $2 \mathrm{~b}$ focuses on comparisons in the olfactory cortex, which appear (nonsignificantly) larger in heterosexual women as compared to both bisexual and homosexual women. 
Appendix Figure 3a

- Heterosexual Men vs. • Homosexual Men
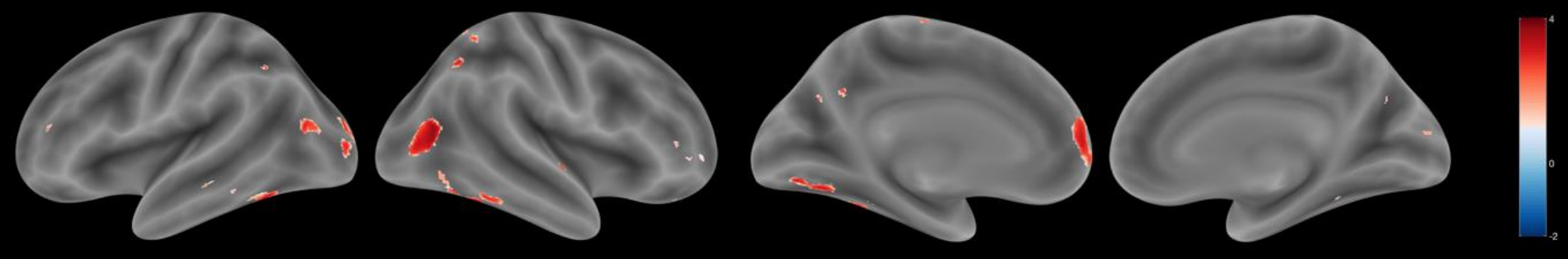

- Bisexual Men vs. • Homosexual Men
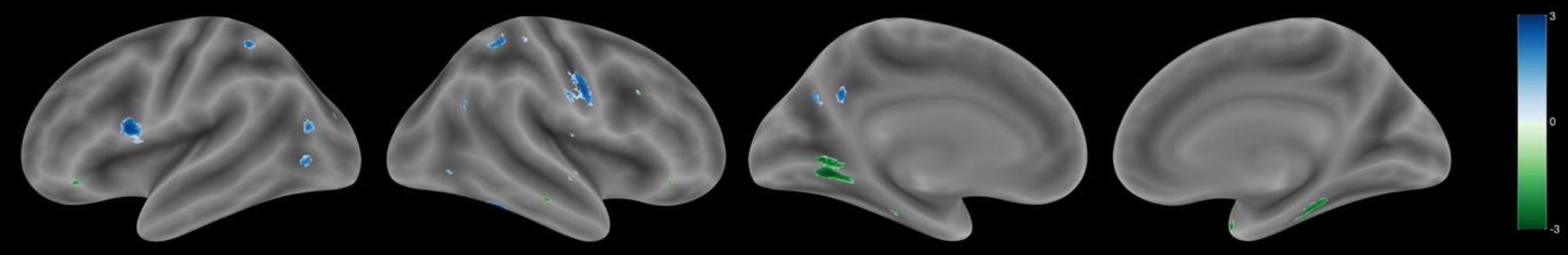

- Bisexual Men vs. • Heterosexual Men
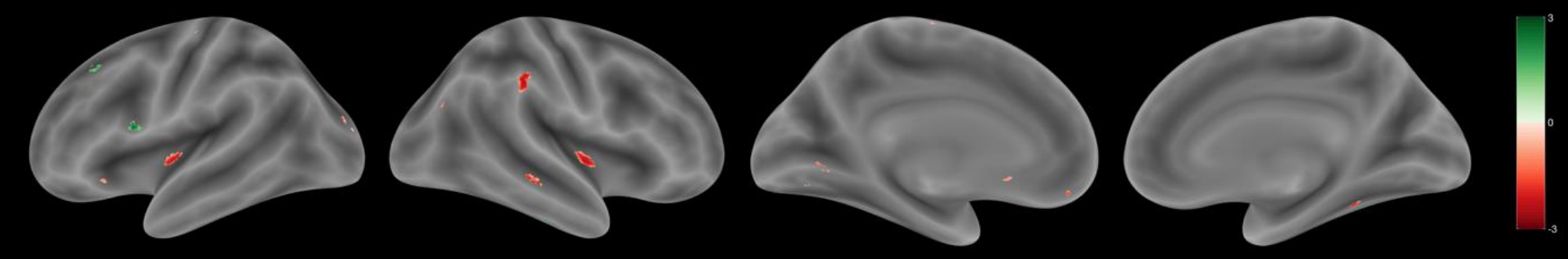


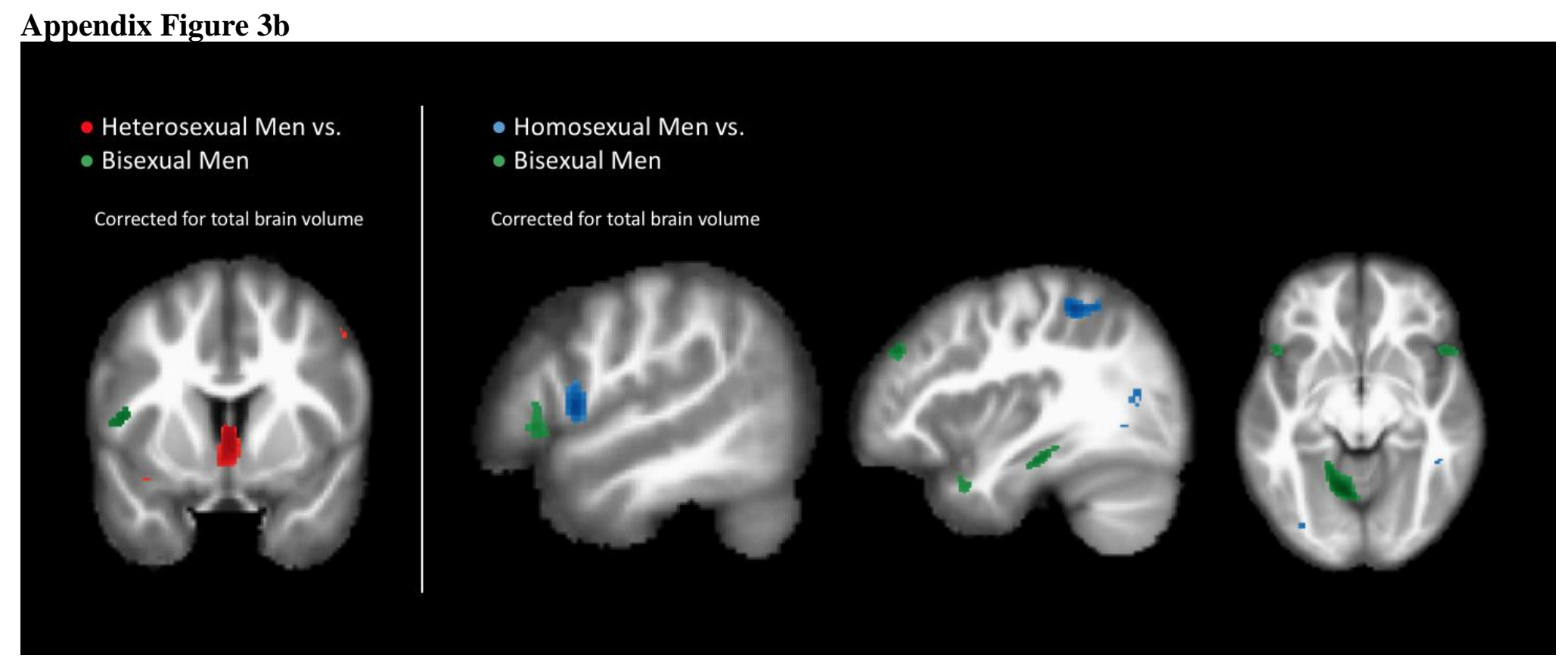

$3 \mathrm{a}$ and $3 \mathrm{~b}$. Non-significant comparisons of gray matter volume between male orientation groups (adjusted for age and total intracranial volume). All panels show results obtained with an uncorrected threshold of $\mathrm{p}<.01$ and voxel cutoff of $\mathrm{k}=5$. Due to the lack of statistical correction, these maps should not be considered to represent significant results. Due to the relatively small variability of brain volume within sex (as opposed to between sex), similar patterns emerge for withinsex orientation comparisons regardless of brain volume correction. The left side of Figure $3 \mathrm{~b}$ shows an area extending from the caudate to the septum pellucidum with (non-significantly) greater volume in heterosexual than in bisexual men. The first sagittal slice on the right side of Figure $3 \mathrm{~b}$ shows two frontal areas that have opposite-direction volumetric patterns. Homosexual men have a non-significantly larger area than bisexual men in left pars opercularis, and bisexual men have a non-significantly larger area than homosexual men in left pars triangularis extending into left pars orbitalis. 